University of Nebraska - Lincoln

DigitalCommons@University of Nebraska - Lincoln

Publications from USDA-ARS / UNL Faculty

U.S. Department of Agriculture: Agricultural

Research Service, Lincoln, Nebraska

2017

\title{
In Vivo Tracking of Copper-64 Radiolabeled Nanoparticles in Lactuca sativa
}

Ryan A. Davis

Radiochemistry Research and Training Facility

Devin A. Rippner

Department of Land, Air and Water Resources

Sven H. Hausner

Radiochemistry Research and Training Facility

Sanjai J. Parikh

Department of Land, Air and Water Resources, sjparikh@ucdavis.edu

Andrew J. McElrone

USDA-ARS

See next page for additional authors

Follow this and additional works at: https://digitalcommons.unl.edu/usdaarsfacpub

Davis, Ryan A.; Rippner, Devin A.; Hausner, Sven H.; Parikh, Sanjai J.; McElrone, Andrew J.; and Sutcliffe, Julie L., "In Vivo Tracking of Copper-64 Radiolabeled Nanoparticles in Lactuca sativa" (2017). Publications from USDA-ARS / UNL Faculty. 1767.

https://digitalcommons.unl.edu/usdaarsfacpub/1767

This Article is brought to you for free and open access by the U.S. Department of Agriculture: Agricultural Research Service, Lincoln, Nebraska at DigitalCommons@University of Nebraska - Lincoln. It has been accepted for inclusion in Publications from USDA-ARS / UNL Faculty by an authorized administrator of DigitalCommons@University of Nebraska - Lincoln. 


\section{Authors}

Ryan A. Davis, Devin A. Rippner, Sven H. Hausner, Sanjai J. Parikh, Andrew J. McElrone, and Julie L. Sutcliffe 


\title{
In Vivo Tracking of Copper-64 Radiolabeled Nanoparticles in Lactuca sativa
}

\author{
Ryan A. Davis, ${ }^{\dagger, \$ \odot}$ Devin A. Rippner, ${ }^{\S}$ Sven H. Hausner, ${ }^{\dagger, \$}$ Sanjai J. Parikh, ${ }^{\S}$ Andrew J. McElrone, \\ and Julie L. Sutcliffe ${ }^{*, \dagger, \ddagger, \perp, \#}$
}

${ }^{\dagger}$ Department of Internal Medicine, Division of Hematology \& Oncology, ${ }^{\ddagger}$ Radiochemistry Research and Training Facility, ${ }^{\S}$ Department of Land, Air and Water Resources, "USDA-ARS, Department of Viticulture and Enology, ${ }^{\perp}$ Department of Biomedical Engineering, and ${ }^{\#}$ Center for Molecular and Genomic Imaging, University of California-Davis, 2921 Stockton Blvd, Sacramento, California 95817, United States

\section{Supporting Information}

ABSTRACT: Engineered nanoparticles (NPs) are increasingly used in commercial products including automotive lubricants, clothing, deodorants, sunscreens, and cosmetics and can potentially accumulate in our food supply. Given their size it is difficult to detect and visualize the presence of NPs in environmental samples, including crop plants. New analytical tools are needed to fill the void for detection and visualization of NPs in complex biological and environmental matrices. We aimed to determine whether radiolabeled NPs could be used as a noninvasive, highly sensitive analytical tool to quantitatively track and visualize NP transport and accumulation in vivo in lettuce (Lactuca sativa) and to investigate the effect of NP size on transport and distribution over time using a combination of autoradiography, positron emission tomography (PET)/computed tomography (CT), scanning electron microscopy (SEM), and transition electron microscopy (TEM). Azide functionalized NPs were radiolabeled via a "click" reaction with copper-64 $\left({ }^{64} \mathrm{Cu}\right)$-1,4,7-triazacyclononane triacetic acid (NOTA) azadibenzocyclooctyne (ADIBO) conjugate ([ $\left.{ }^{64} \mathrm{Cu}\right]-$ ADIBO-NOTA) via copper-free Huisgen-1,3-dipolar cycloaddition reaction. This yielded radiolabeled [ $\left.{ }^{64} \mathrm{Cu}\right]-\mathrm{NPs}$ of uniform shape and size with a high radiochemical purity (>99\%), specific activity of $2.2 \mathrm{mCi} / \mathrm{mg}$ of $\mathrm{NP}$, and high stability (i.e., no detectable dissolution) over $24 \mathrm{~h}$ across a $\mathrm{pH}$ range of 5-9. Both $\mathrm{PET} / \mathrm{CT}$ and autoradiography showed that $\left[{ }^{64} \mathrm{Cu}\right]-\mathrm{NPs}$ entered the lettuce seedling roots and were rapidly transported to the cotyledons with the majority of the accumulation inside the roots. Uptake and transport of intact NPs was size-dependent, and in combination with the accumulation within the roots suggests a filtering effect of the plant cell walls at various points along the water transport pathway.

\section{INTRODUCTION}

The increasing use of NPs in commercial products has led to $\mathrm{NP}$-accumulation in the environment and within the food chain. ${ }^{1-9}$ Chronic exposure to NPs can lead to health issues as some inorganic NPs have biological activity at the cellular and subcellular level with an unknown cytotoxicity and genotoxicity. ${ }^{3,4,10}$ In particular, metal oxide NPs are the most abundant form of NP in the environment with the most potential toxic risks. ${ }^{7,11}$ Locating, quantifying, and imaging NPs in vivo can provide information on biodistribution and fate of NPs in living systems. ${ }^{12,13}$ However, many challenges to quantitatively assess their biodistributions under realistic environmental exposure concentrations ( $\mathrm{mg} \mathrm{L}^{-1}$ to $\mathrm{ng} \mathrm{L^{-1 }}$ ) remain.

To date, the visualization of most NPs within plants has relied on the use of micro-X-ray fluorescence spectrometry $(\mu$ XRF), confocal microscopy, TEM, SEM, scanning transmission electron microscopy (STEM), or scanning transmission ion microscopy (STIM). ${ }^{14-20}$ The most prominent quantification techniques have been inductively coupled plasma spectroscopy (ICP) utilizing either optically emission spectroscopy (OES) or mass spectrometry (MS). ${ }^{1,14-20}$ In a few cases atomic absorption spectroscopy (AAS) has been used for quantification. $^{21}$ These techniques required mineralization of the plant material generally with hydrogen peroxide and nitric acid, and may not be sufficiently sensitive enough to quantify small changes in the amount of a metal ion. ${ }^{1,22,23}$ Notably, high background concentrations of essential nutrients make detecting and quantifying the small variation in NP-related metal ion content an analytical challenge as the measurement is often of the same magnitude as noise or at the detection limit. ${ }^{1,22,23}$ Optically tagged NPs have also been investigated, but the challenge of overcoming the plants' own bioluminescence can make quantification difficult. ${ }^{24,25}$

Although used in medical imaging, radiolabeled NPs for noninvasive tracking and quantification in plants have not been

Received: July 3, 2017

Revised: September 11, 2017

Accepted: September 27, 2017

Published: September 27, 2017 
significantly explored. ${ }^{12,13}$ Prior radiolabeling of NPs for medical imaging has utilized three main approaches: (1) postradiolabeling via attachment of chelator to NPs first, then reaction with the a metal radionuclide; (2) preradiolabeling, where a radioactive prosthetic group, a small molecule that the radioisotope is attached, followed by attachment to the NP; and (3) direct radiolabeling. ${ }^{13}$ Of these three main radiolabeling approaches, the third approach has been the only method used to study NP distribution in plants where Zhang et al. ${ }^{12}$ reported the use of $\left[{ }^{141} \mathrm{Ce}\right] \mathrm{CeO}_{2}-\mathrm{NPs}$ produced via neutron bombardment of $\mathrm{CeO}_{2}$-NPs to study distribution in cucumbers. The produced radionuclide ${ }^{141} \mathrm{Ce}$ has a 32.51 day half-life, and the specific activity of the synthesized $\left[{ }^{141} \mathrm{Ce}\right] \mathrm{CeO}_{2}-\mathrm{NPs}$ was 2.7 $\mu \mathrm{Ci} / \mathrm{mg}$ of NP. ${ }^{12}$

Despite numerous approaches to analyze NPs, a combination of technologies is required due to the low detection limits (ppb-ppt) and high resolution ( $\mathrm{nm}$ ) needed to address the intact nature of NP-transport into plants. Thus, multiple tools must be utilized to quantify and determine the intact nature of NPs at a given location within biological environments (Figure 1). ${ }^{26}$ Previous studies have provided conflicting evidence about

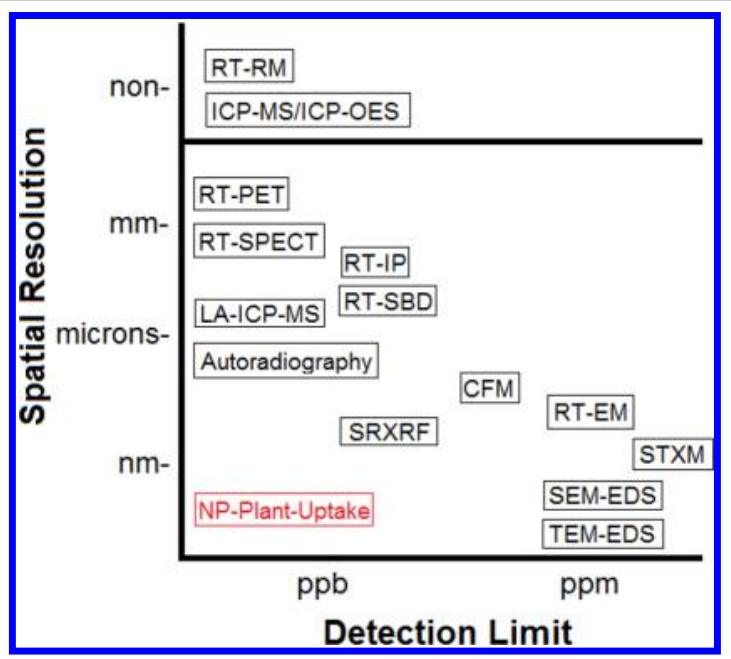

Figure 1. Spatial and quantitative limits of instruments used to identify nanoparticles (Figure adapted from ref 26). Black boxes indicate the analytical method/instrumentation. The red box shows the range of detection and spatial resolution required to quantify and visualize NPs within plants. Abbreviations: RT-radiotracing, RM-radiometry, SPECT-single photon emission computed tomography, IP-imaging plate, SBD-silicon based detector, LA-laser ablation, CFM-confocal fluorescence microscopy, EM-electron microscopy, SRXRF-synchrotron radiation micro-X-ray fluorescence, EDS-energy dispersive $\mathrm{x}$-ray spectroscopy, and STXM-scanning transmission X-ray microscopy. Instruments at top do not have spatial resolution (RT-RM and ICP).

the intact nature of NP uptake and transport into plants: some studies indicated intact NP uptake and vascular transport, ${ }^{10,12,15,16,20,27-32}$ some observed NPs in plants due to dissolution events and reformation within the plant tissue, ${ }^{14,17-19,33-35}$ and still others have indicated that NPs cannot be transported into plants. ${ }^{2,36-38}$ These varied observations could be linked to inadequate techniques available to track NP movement in vivo. The main challenge in determining intact NP transport into plants is ruling out NPdissolution, as reductive precipitation and formation of NPs within plant tissue has been documented. ${ }^{39-43}$ Even natural formation of NPs within plants and fungi is known. ${ }^{44}$ Further complicating the picture is the fact that many studies assessing
NP uptake exposed plants over long periods of time from 2 to 130 days, with very large amounts of NPs (500-10000 mg $\mathrm{L}^{-1}$ ) per plant, which could make dissolution events more prevalent. ${ }^{1,10,16-32,36,45}$ Avoiding excessive exposure to the NPs (both, in concentration and time) and carefully analyzing the stability of the administered NPs are key to avoid erroneous conclusions due to NP-dissolution and subsequent reformation.

In this study we evaluated an analytical method using a radioactive label to noninvasively track and quantify transport and accumulation of NPs in lettuce seedlings in vivo. This method studied NP-size dependent transport immediately upon exposure ( $<1$ day), an early time frame that has rarely been explored in plants. ${ }^{31}$ The visualization of NP transport and accumulation in lettuce seedlings was done by autoradiography and $\mathrm{PET} / \mathrm{CT}$ imaging and further confirmed by gamma-counting, SEM, and TEM. Our study was designed to use highly uniform NPs (shape and size) of two size sets (10 and $20 \mathrm{~nm}$ ), which were theoretically too large for passive transport across plant tissues (pore size $\leq 2 \mathrm{~nm}$ ). ${ }^{, 7}$ To ensure a narrow size distribution with a uniform geometric shape and the ability to thoroughly investigate stability (i.e., no dissolution and reprecipitation inside the plant), a preradiolabeling method with the PET-radioisotope copper-64, the "clickable" chelator ADIBO-NOTA, and commercially available spherical $\mathrm{Fe}_{3} \mathrm{O}_{4}$ NPs containing azides was explored. This radiolabeling approach yielded a high specific activity $(\mathrm{mCi} / \mathrm{mg}$ of $\mathrm{NP}$ ) and allowed for size characterization of the NPs after the plant accumulation and imaging period, and avoided complication from fabricating radioactive NPs and production of less stable NP material with a larger size distribution. Rigorous stability studies were carried out at a variety of $\mathrm{pHs}$ to investigate possible dissolution of the ${ }^{64} \mathrm{Cu}$-radiolabeled NPs and substantiate the intact nature of NP-transport into lettuce seedlings.

\section{MATERIALS AND METHODS}

Hydroponic Culture. Lettuce (Lactuca sativa "Green Towers") seeds were germinated at $25{ }^{\circ} \mathrm{C}$ in Petri dishes hydroponically in Hoagland's solution containing: $210 \mathrm{mg} \mathrm{L}^{-1}$ of nitrogen, $235 \mathrm{mg} \mathrm{L}^{-1}$ of potassium, $200 \mathrm{mg} \mathrm{L}^{-1}$ calcium, 31 $\mathrm{mg} \mathrm{L}^{-1}$ phosphorus, $64 \mathrm{mg} \mathrm{L}^{-1}$ sulfur, $48 \mathrm{mg} \mathrm{L}^{-1}$ magnesium, $0.5 \mathrm{mg} \mathrm{L}^{-1}$ boron, $1.35 \mathrm{mg} \mathrm{L}^{-1}$ iron, $0.5 \mathrm{mg} \mathrm{L}^{-1}$ manganese, $0.05 \mathrm{mg} \mathrm{L}{ }^{-1}$ zinc, $0.02 \mathrm{mg} \mathrm{L}^{-1}$ copper, and $0.01 \mathrm{mg} \mathrm{L}^{-1}$ molybdenum. Seedlings were grown in the dark for 7 days and then transferred to constant light for 2 days prior to use in the experiment. The length and mass of the lettuce seedlings were approximately $7 \pm 4 \mathrm{~cm}$ and $25 \pm 5 \mathrm{mg}$.

Synthesis of Ligand ADIBO-NOTA (6). Unless specified all reagents were purchased from Sigma-Aldrich and used without further purification. The clickable ligand NOTAADIBO (6) was synthesized following modified literature procedures. ${ }^{46,47}$ Briefly: 5-dibenzosuberenone (1) (5.0 g, 24.3 mmol) was reacted with $N$-hydroxylamine ( 1.5 equiv, $2.5 \mathrm{~g}$, $36.4 \mathrm{mmol}$ ) in pyridine (Acros, $25 \mathrm{~mL}$ ) at $80{ }^{\circ} \mathrm{C}$ overnight, followed by the acid catalyzed Beckmann rearrangement with polyphosphoric acid $(50 \mathrm{~mL})$ at $125^{\circ} \mathrm{C}$. Subsequent reduction of the amide in diethyl ether (Acros, $63 \mathrm{~mL}$ ) with lithium aluminum hydride $\left(\mathrm{LiAlH}_{4}, 2.0\right.$ equiv, $\left.1.84 \mathrm{~g}, 48.6 \mathrm{mmol}\right)$ afforded amine (2) (Scheme 1), which was reacted in $N, N$ dimethylformamide (DMF) (EMD, $3 \mathrm{~mL}$ ) with $N$-[(dimethylamino)-1H-1,2,3-triazolo-[4,5-b] pyridin-1-ylmethylene]-Nmethylmethan-aminiumhexafluorophosphate $\mathrm{N}$-oxide (HATU, GL Biochem, 2.8 equiv, $250 \mathrm{mg}, 0.653 \mathrm{mmol}$ ) and 
Scheme 1. Synthesis of ligand ADIBO-NOTA (6)

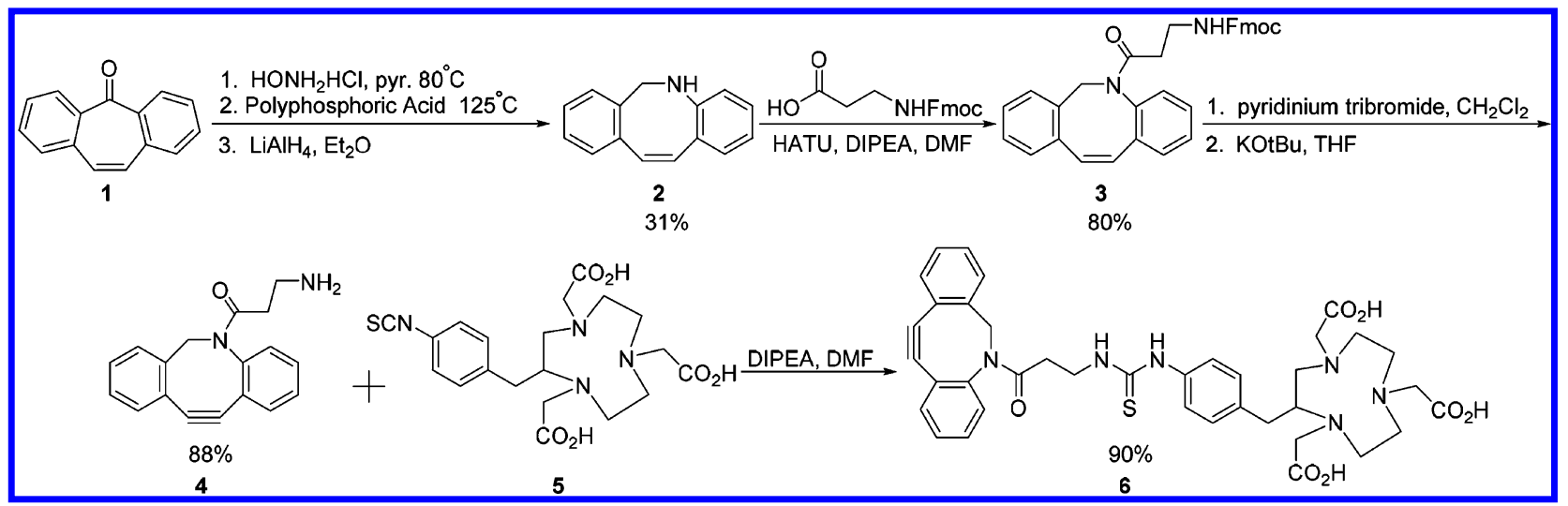

Scheme 2. Radiolabeling and Assembly of $\left[{ }^{64} \mathrm{Cu}\right]-\mathrm{NPs}$

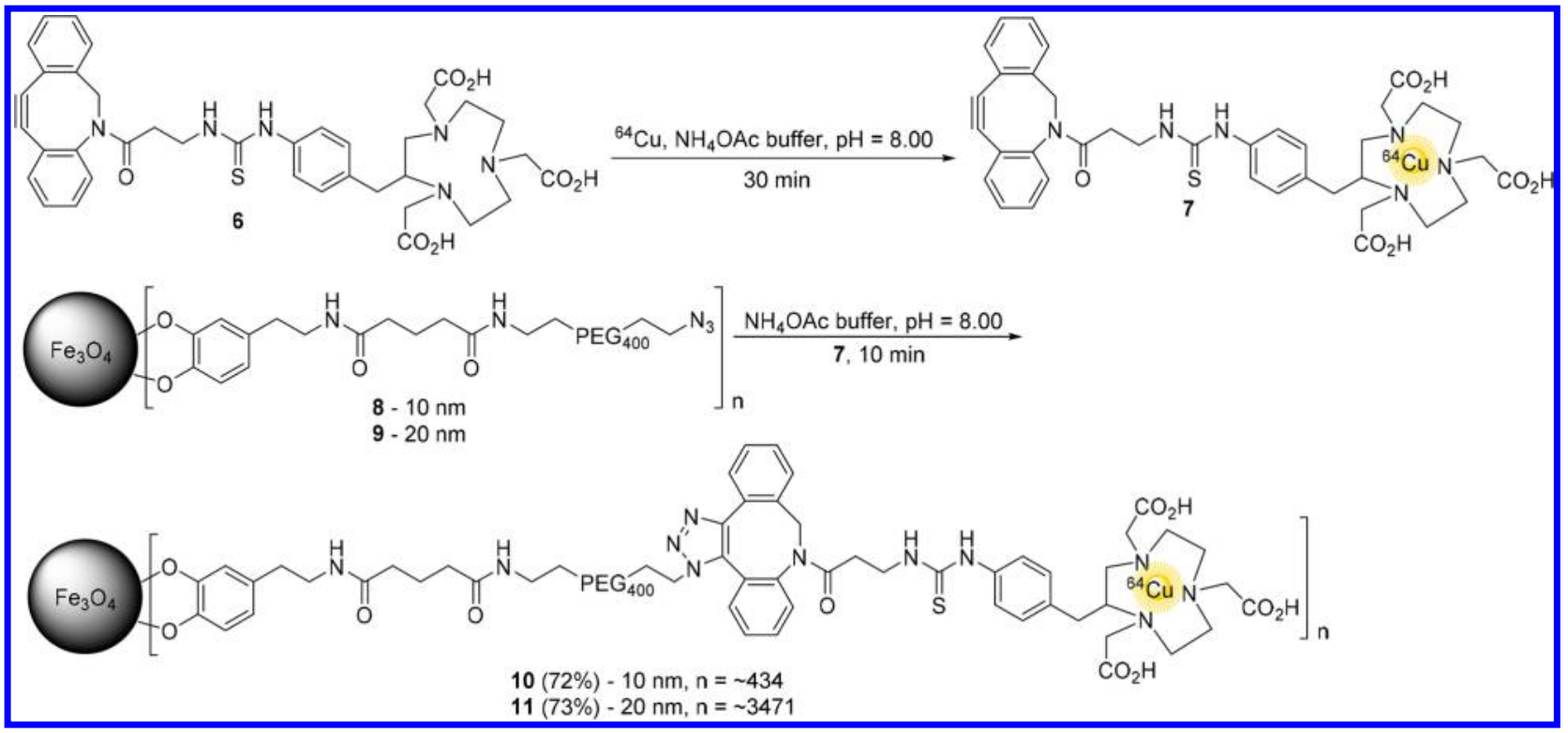

diisopropylethylamine (DIPEA, 6.0 equiv, $250 \mu \mathrm{L}, 1.45 \mathrm{mmol}$ ) activated $N$-Fmoc- $\beta$-alanine (Novabiochem, 3 equiv, $226 \mathrm{mg}$, $0.726 \mathrm{mmol}$ ) to afford 3 . Compound 3 was bis-brominated with pyridinium tribromide and upon double elimination of the bromides with potassium $t$-butoxide ( 2.5 equiv), strained cyclooctyne (4) was produced. Compound 4 was then reacted with 2-( $p$-isothiocyanatobenzyl)-1,4,7-triazacyclononane$N, N^{\prime}, N^{\prime \prime}$-triacetic acid (5) ( $p$-SCN-Bn-NOTA, Macrocyclics, 1.0 equiv, $1 \mathrm{mg}, 0.0017 \mathrm{mmol})$ in DMF $(100 \mu \mathrm{L})$ and DIPEA $(5 \mu \mathrm{L})$ to afford NOTA-ADIBO (6) $(1.09 \mathrm{mg}, 0.0015 \mathrm{mmol})$ (Scheme 1). The NOTA-ADIBO ligand (6) was purified and analyzed by reversed phase-high performance liquid chromatography (RP-HPLC) jupiter-proteo-C12-column (Phenomenex, $250 \mathrm{~mm} \times 4.6 \mathrm{~mm} \times 4 \mu \mathrm{m}$ ), a mobile phase gradient held for $2 \mathrm{~min}$ at $9 \%$ acetonitrile in $0.05 \%$ trifluoroacetic acid (TFA) aqueous solution and increased to $81 \%$ acetonitrile over $30 \mathrm{~min}$ at a flow rate of $1.5 \mathrm{~mL} / \mathrm{min}$. Purified compound (6) was confirmed by mass spectroscopy using electrospray ionization scanning (ESI) for positive ions (Orbitrap, Thermo-Fisher Scientific) (S2).

Radiolabeling and Assembly of $\left[{ }^{64} \mathrm{Cu}\right]-N P s$. The ADIBO-NOTA (6) $(400 \mu \mathrm{L}, 1 \mathrm{mg} / \mathrm{mL}$ solution in DI water) was used to chelate ${ }^{64} \mathrm{Cu}\left(\left[{ }^{64} \mathrm{Cu}\right] \mathrm{CuCl}_{2}, 4.4-6 \mathrm{mCi}\right.$, half-life$12.7 \mathrm{~h}$ ) in an aqueous solution of ammonium acetate
$\left(\mathrm{NH}_{4} \mathrm{OAc}\right)$ at $\mathrm{pH}=8.00(405 \mu \mathrm{L})$ for $30 \mathrm{~min}$ at room temperature to produce 7 , which was used without further purification. Commercially available azide functionalized catechol-PEG coated $\mathrm{Fe}_{3} \mathrm{O}_{4}$-NPs (AC Diagnostic, Inc.) (8, 10 $\mathrm{nm})$ or $(9,20 \mathrm{~nm}),(1 \mathrm{mg}$ of NP, $200 \mu \mathrm{L}$ of $5 \mathrm{mg} / \mathrm{mL}$ solution) were each reacted with $7(400 \mu \mathrm{L}, 2.2 \mathrm{mCi})$ for $10 \mathrm{~min}$ at room temperature to afford $\mathbf{1 0}$ or $\mathbf{1 1}$, respectively (Scheme 2). Radioactive $\left[{ }^{64} \mathrm{Cu}\right]$-NPs $(10$ and 11$)$ were diluted with $600 \mu \mathrm{L}$ of DI water to a total volume of $1.2 \mathrm{~mL}$ and purified using a P6gel size exclusion spin column (Bio-Rad). Incorporation of ${ }^{64} \mathrm{Cu}$ into 6 and conjugation to NPs (8 and 9) was monitored by RP-HPLC (jupiter-proteo-C12-column,Phenomenex, 250 $\mathrm{mm} \times 4.6 \mathrm{~mm} \times 4 \mu \mathrm{m}$ ), a mobile phase gradient held for $2 \mathrm{~min}$ at $9 \%$ acetonitrile in $0.05 \%$ trifluoroacetic acid aqueous solution and increased to $81 \%$ acetonitrile over $30 \mathrm{~min}$ at a flow rate of $1.5 \mathrm{~mL} / \mathrm{min}$. A $10 \mu \mathrm{L}$ aliquot of each 10 and 11 was diluted with $250 \mu \mathrm{L}$ of $0.1 \mathrm{M}$ ethylenediaminetetraacetic acid (EDTA) solution and the NPs filtered off via a membrane filter (40 000 molecular weight cut off) by centrifugation (3000 rcf, $4 \mathrm{~min}$ $(4 \times))$. The filtrate was analyzed by injection onto RP-HPLC as described above. The HPLC-system consisted of a UV-detector (wavelength-220 $\mathrm{nm}$ ) and a radioactivity detector (PMT) connected in series. Radiochemical purity was also confirmed by thin-layer chromatograpy (TLC) by spotting the EDTA- 
challenged filtrate onto an TLC strip, running with $1.0 \mathrm{M}$ $\mathrm{NH}_{4} \mathrm{OAc}$ buffer $\mathrm{pH}=8.0$, and reading on a radioTLC-scanner (Bioscan 3000)(S3).

Characterization of Iron Oxide $\left(\mathrm{Fe}_{3} \mathrm{O}_{4}\right)$ NPs. Spherical iron oxide $\left(\mathrm{Fe}_{3} \mathrm{O}_{4}\right)$ NPs (8 and 9), functionalized with catechol-PEG ${ }_{400}$-azide ligand were purchased from AC Diagnostic, Inc., (diameter: 10 and $20 \mathrm{~nm}$ ). The exact size for each batch of NPs (10 nm (8) and $20 \mathrm{~nm} \mathrm{(9))} \mathrm{was}$ determined by TEM by finding the mean diameter $(n>200)$. The hydrodynamic diameter was determined by dynamic light scattering (DLS) and the zeta-potential found. This was done for both the azide containing NPs and the functionalized conjugated NPs (10 and 11) (S5).

TEM Size Determination of NPs. Primary particle size and shape of the $\mathrm{Fe}_{3} \mathrm{O}_{4}$-NPs was characterized by TEM (Philips CM-12) at $120 \mathrm{kV}$. Samples were prepared for TEM analysis by placing $10 \mu \mathrm{L}$ of a stock $\mathrm{Fe}_{3} \mathrm{O}_{4}$-NP suspension on Formvar film coated $\mathrm{Cu}$ grids (Ted Pella) and drying the grids over an incandescent bulb. Mean primary particle size $(n>200)$ for all $\mathrm{Fe}_{3} \mathrm{O}_{4}$-NP samples $(8-11)$ of both sizes $(10$ and $20 \mathrm{~nm})$ was calculated from TEM images using Fiji-software (S5).

Dynamic Light Scattering (DLS) Hydrodynamic Size and Zeta-Potential Determination of NPs. Hydrodynamic radius data were collected after sample dispersion $\left(100 \mathrm{mg} \mathrm{L}^{-1}\right.$ of $\mathrm{Fe}_{3} \mathrm{O}_{4}$-NPs $(8-11)$ ) in $1 \mathrm{mM} \mathrm{KCl}$ and $1 / 2$ Hoagland's solution by dynamic light scattering at a wavelength of $660 \mathrm{~nm}$ using a ZetaPlus (Brookhaven Instruments Corp.). Zetapotentials were calculated using ZetaPlus software after determining particle electrophoretic mobility (S5).

Stability of $\left[{ }^{64} \mathrm{Cu}\right]-N P s$. The stability of the $\left[{ }^{64} \mathrm{Cu}\right]-\mathrm{NPs} \mathbf{1 0}$ and 11 was assessed over a $\mathrm{pH}$ range $(5.0,6.0,7.0,8.0$, and 9.0) up to $12 \mathrm{~h}$ : Radiolabeled $\left[{ }^{64} \mathrm{Cu}\right]-\mathrm{NPs} 10$ and $11(30 \mu \mathrm{L}, \sim 50$ $\mu \mathrm{Ci}$ ) were incubated in $1 \mathrm{~mL}$ of $1.0 \mathrm{M}$ ammonium acetate at the given $\mathrm{pH}$ for 4,8 , and $12 \mathrm{~h}$. At each time point for each $\mathrm{pH}$, the $\left[{ }^{64} \mathrm{Cu}\right]$-NPs were filtered with a membrane filter $(40000$ molecular weight cut off) by centrifugation at $3000 \mathrm{rcf}$ for 4 min $(4 \times)$. The filtrate was evaluated with a gamma counter (Wizard1470, PerkinElmer) for radioactivity (loss of ${ }^{64} \mathrm{Cu}$ or $\left[{ }^{64} \mathrm{Cu}\right]$-ligand) and by HPLC for UV signal (loss of ligand) (S4). Additionally, the stability of $\left[{ }^{64} \mathrm{Cu}\right]-\mathrm{NPs}(\mathbf{1 0}$ and $\mathbf{1 1})$ was reconfirmed at $15 \mathrm{~min}, 12 \mathrm{~h}$, and $24 \mathrm{~h}$ post exposure to the lettuce seedlings by filtering off the $\left[{ }^{64} \mathrm{Cu}\right]$-NPs and examining the filtrate in the same manner (S4).

Administration of $\left[{ }^{64} \mathrm{Cu}\right]-\mathrm{NPs}$ to Plants (Time Course Study). Purified $\left[{ }^{64} \mathrm{Cu}\right]$-NPs 10 and $11(20 \mu \mathrm{L}, \sim 0.0167 \mathrm{mg}$ NP, per plant) were exposed to lettuce seedlings $(n=3)$ per time point ( $15 \mathrm{~min}, 30 \mathrm{~min}, 1 \mathrm{~h}, 2 \mathrm{~h}, 4 \mathrm{~h}, 12 \mathrm{~h}, 24 \mathrm{~h}$ ). The $\left[{ }^{64} \mathrm{Cu}\right]$-NPs 10 and 11 suspension was placed into a PCR-tube and diluted up to $350 \mu \mathrm{L}$ with DI water to give a final concentration of $48 \mathrm{mg} \mathrm{L}{ }^{-1}$ of $\left[{ }^{64} \mathrm{Cu}\right]-\mathrm{NP}$ per plant with an activity range between 30 and $34 \mu \mathrm{Ci}(32 \pm 2 \mu \mathrm{Ci})$. Plants were then placed into the PCR-tube with only the lower portion of the root exposed to the $\left[{ }^{64} \mathrm{Cu}\right]-\mathrm{NP}$ suspension (lower $2 \mathrm{~cm}$ ). The experiment was performed at ambient temperature (22 ${ }^{\circ} \mathrm{C}$ ) and lighting from incandescent light bulbs. At the end of each time point the plants were removed and the roots were rinsed with DI water $(3 \times)$ and soaked for $1 \mathrm{~h}$ in a solution containing 10\%-Triton100X (200 $\mu \mathrm{L}$, ThermoScientific) and $0.1 \mathrm{M}$ EDTA (200 $\mu \mathrm{L}$, Sigma-Aldrich) and DI water $(200 \mu \mathrm{L})$, and rinsed again with DI water $(3 \mathrm{X})$; plants were divided into the cotyledons and root portions. Each portion was weighed and radioactivity determined by the gamma counter. Two additional sets of lettuce plants for each set of $\left[{ }^{64} \mathrm{Cu}\right]-\mathrm{NP}$ were given double (40 $\mu \mathrm{L}$ of NP, $96 \mathrm{mg} \mathrm{L}^{-1}, \sim 60 \mu \mathrm{Ci}, n=3$ ) and triple ( $60 \mu \mathrm{L}$ of NP, $144 \mathrm{mg} \mathrm{L}^{-1} \sim 90 \mu \mathrm{Ci}, n=3$ ) the amount of NPs for a single uptake period of $2 \mathrm{~h}$ to examine concentration dependence uptake.

Autoradiography and PET/CT Imaging of $\left[{ }^{64} \mathrm{Cu}\right]-\mathrm{NP}$ in Lettuce. Immediately after gamma-counting and weighing, the plants were exposed to a storage phosphor screen (GE Healthcare) overnight $(\sim 16 \mathrm{~h})$. The screen was read at 50 $\mu \mathrm{m}$ resolution using a Storm 860 phosphorimager (GE Healthcare) and visualized using ImageJ software (Version 1.46r, National Institutes of Health). PET/CT imaging was performed on 3 plants at the $2 \mathrm{~h}$ time point. For imaging, the lettuce was placed between two pieces of agarose gel to help with hydration. A static 15 min PET emission scan was acquired on an Inveon-DPET scanner (Siemens Medical Solutions) followed by computed tomography (CT) scan and processed with the Inveon Research Workplace software (Siemens).

Scanning Electron Microscopy (SEM) of Lettuce Roots. After autoradiography the plants were dehydrated in ethanol ( 1 day) followed by acetone ( 1 day). Once the radioactivity decayed to background samples were dried under vacuum for 1 day and the adherence of NPs to the surface of the root was examined by scanning electron microscopy (SEM; FEI XL30) at $5 \mathrm{kV}$, followed by energy dispersive X-ray analysis for elemental analysis.

Transmission Electron Microscopy (TEM) of Lettuce Roots and Cotyledons. To correlate $\left[{ }^{64} \mathrm{Cu}\right]-\mathrm{NP}$ location in the PET/CT and autoradiography images to TEM images, the plant tissue was fixed in Karnovski's fixative, post fixed in $1 \%$ osmium tetroxide, dehydrated in cold acetone and infiltrated with Epon/Aradite (Ted Pella). Once the radioactivity decayed to background, the plant samples were cross-sectioned and cut with an Ultra 45 diamond knife (Diatome). The thin sections of fixed, infiltrated plant tissue were then mounted on Formvar film coated $\mathrm{Cu}$ grids (Ted Pella) and imaged by TEM (JEOL 2500SE) at $200 \mathrm{kV}$.

\section{RESULTS}

Synthesis, Radiolabeling, and Assembly of NPs. The synthesis of ADIBO-NOTA (6) provided an overall yield of $20 \%$, which was comparable to those reported following modified literature protocols ${ }^{46,47}$ and was chelated to ${ }^{64} \mathrm{Cu}$ to give 7 with a radiochemical purity of $98 \%$ (Scheme 2). The molar activity of radiolabeled ligand 7 was $7297.3 \mathrm{Ci} / \mathrm{mol}$. The attachment of 7 to either 8 or 9 provided approximately the same average radiochemical yield of $72 \%$ and $73 \%$, respectively ( $n=18$ spin columns per NP-size, radiochemical yield range $65-80 \%)$ of 10 and 11, respectively, after purification via P6gel size exclusion spin-column with a specific activity of 2.24 $\mathrm{mCi} / \mathrm{mg}$ of $\left[{ }^{64} \mathrm{Cu}\right]-\mathrm{NP}$ and a radiochemical purity of $>99 \%$ for both sized $\left[{ }^{64} \mathrm{Cu}\right]-\mathrm{NP}$ (Scheme 2). Both TLC and RP-HPLC analysis showed no observable UV or radiation signals associated with EDTA-complexed- ${ }^{64} \mathrm{Cu}$ (nonchelated ${ }^{64} \mathrm{Cu}$ ion) and upon "clicking" no observed radioactive ligand was observed (S3).

Characterization and Size Determination of NPs. Characterization of the commercially available azide-functionalized NPs 8 and 9 by TEM illustrated that the NPs do not aggregate readily and were spherical in shape. The mean size for the smaller NPs $(8,10 \mathrm{~nm})$ was $9 \pm 2 \mathrm{~nm}$ and for the larger NPs $(9,20 \mathrm{~nm})$ was $19 \pm 3 \mathrm{~nm}$. NPs (10 and 11) showed no change in size by TEM, however, the DLS hydrodynamic radius 


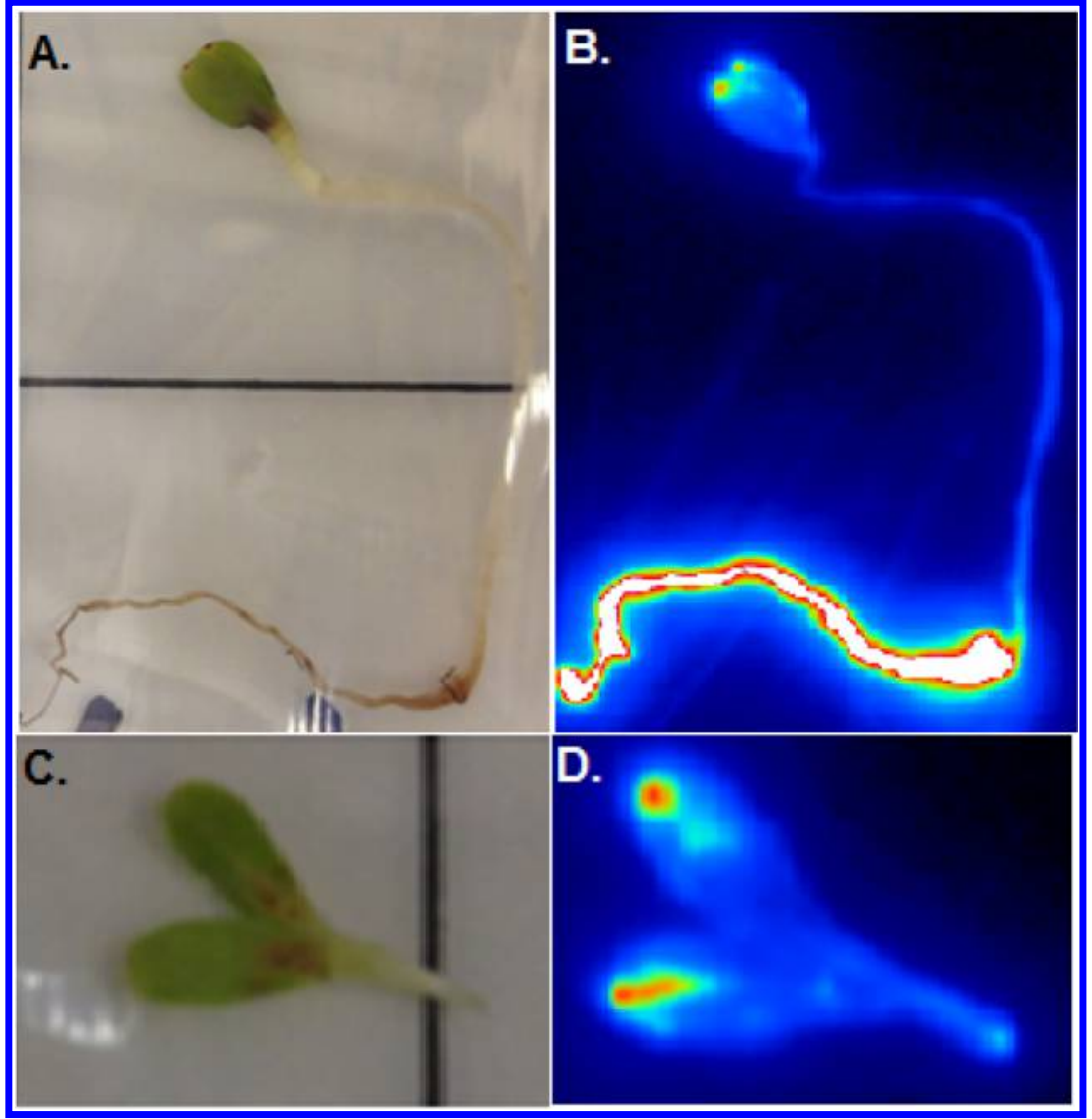

Figure 2. Representative autoradiography image of the lettuce seedling after $2 \mathrm{~h}$ exposure to $\left[{ }^{64} \mathrm{Cu}\right]-\mathrm{NPs}(\mathbf{1 1})$. A. Actual photographic image of lettuce seedling. B. Rainbow color scale autoradiography image of the same lettuce seedling. $\mathrm{C}$ and $\mathrm{D}$. Representative autoradiography image of the cotyledons removed after $\left[{ }^{64} \mathrm{Cu}\right]-\mathrm{NP}(11)$ uptake period $(2 \mathrm{~h})$. C. Actual photographic image of lettuce cotyledon. D. Rainbow color scale autoradiography image of lettuce cotyledon. Rainbow color scale: white-highest activity to dark blue-lowest activity.

decreased after "clicking" the ligand, most likely due to added sterics and hydrophobicity providing a smaller hydrodynamic radius. The zeta-potential ranged from -40 to $-55 \mathrm{mV}$, indicating good colloidal dispersion stability (Table S5).

Stability of $\left[{ }^{64} \mathrm{Cu}\right]-N P$. RP-HPLC analysis of $\mathbf{1 0}$ and $\mathbf{1 1}$ after purification via P6-gel size exclusion spin column and after incubation with the plants $(15 \mathrm{~min}, 12 \mathrm{~h}$, and $24 \mathrm{~h})$ showed no free ${ }^{64} \mathrm{Cu}$ or ${ }^{64} \mathrm{Cu}$-ligand, indicating that once attached, ligand 7 was stable. The conjugated $\left[{ }^{64} \mathrm{Cu}\right]-\mathrm{NP}(10$ and 11$)$ were also stable at all $\mathrm{pH}$ 's (5-9) up to $12 \mathrm{~h}$ by RP-HPLC (S4). Furthermore, the NP filtrates up to $24 \mathrm{~h}$ exposure to the lettuce, also exhibited only background levels of radiation by gamma-counting and no UV or radiation signal by RP-HPLC analysis (S4), signifying no loss of ligand or leaching of ${ }^{64} \mathrm{Cu}$ during the time frame of plant uptake and imaging. TEM was also performed on $\left[{ }^{64} \mathrm{Cu}\right]-\mathrm{NPs}(\mathbf{1 0}$ and $\mathbf{1 1})$ after the radioactivity had decayed to background; the size distribution and aggregation properties remained unchanged, indicating a low propensity to dissolute during the plant NP uptake period (S5).

Imaging of Lettuce Seedling Uptake of $\left[{ }^{64} \mathrm{Cu}\right]-N P$ (10 and 11): Autoradiography and PET/CT Imaging. Figures 2 and 3 show a representative autoradiography and PET/CT images demonstrating uptake of $\left[{ }^{64} \mathrm{Cu}\right]-\mathrm{NPs}(\mathbf{1 0}$ and $\mathbf{1 1})$ into lettuce seedlings. The appearance of the $\left[{ }^{64} \mathrm{Cu}\right]-\mathrm{NPs}$ in the cotyledons (Figures 2 and 3 ) in the lettuce seedlings indicate that NPs moved radially across the root tissue submerged in the $\left[{ }^{64} \mathrm{Cu}\right]-\mathrm{NP}$-suspension, up the root axis (likely traveling

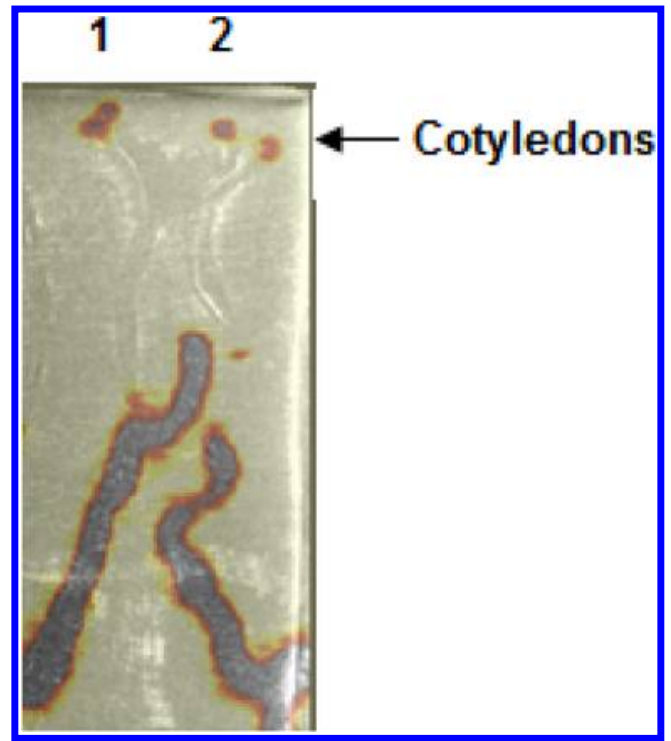

Figure 3. Representative PET/CT image of $\left[{ }^{64} \mathrm{Cu}\right]-\mathrm{NPs}(\mathbf{1 1})$ after a 2 $\mathrm{h}$ uptake in two lettuce seedlings. Plants 1 and 2 show $\left[{ }^{64} \mathrm{Cu}\right]-\mathrm{NPs}$ (11) in cotyledons.

through early stages of the developing vascular tissue), and into the developing shoot along with water flow. A build-up of $\left[{ }^{64} \mathrm{Cu}\right]$-NPs was observed in locations where the root radicle made a bend or turn as seen in some of the autoradiography images (Figures 2 and S9), with the majority of the radioactivity 


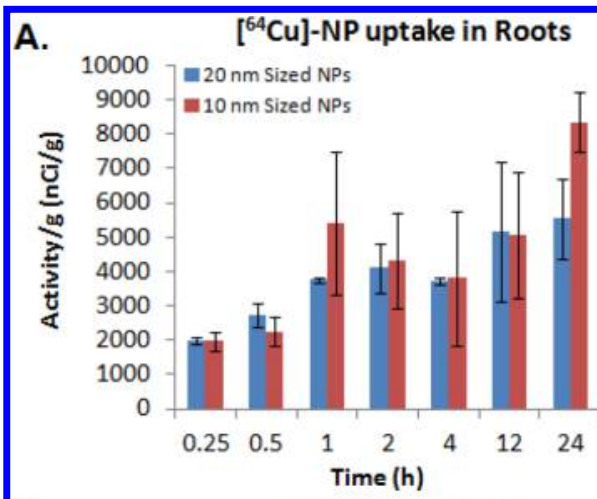

B.

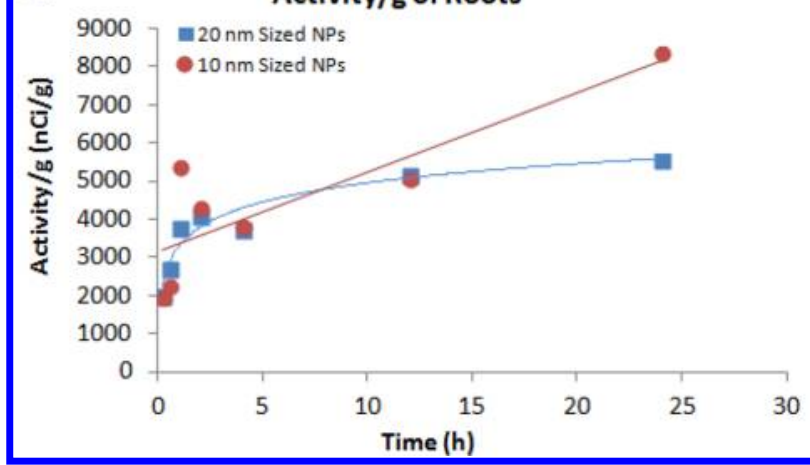

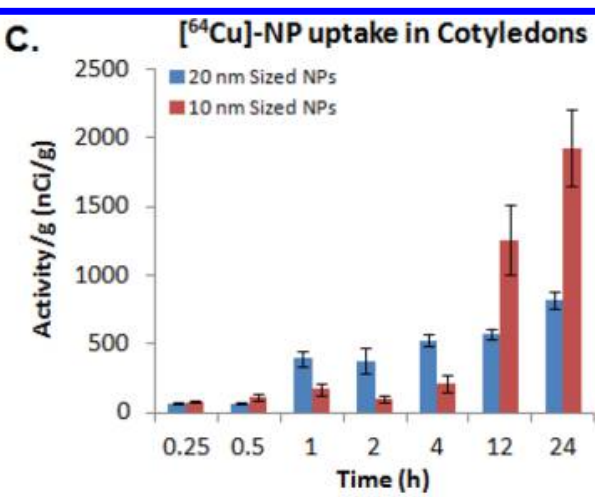

D.

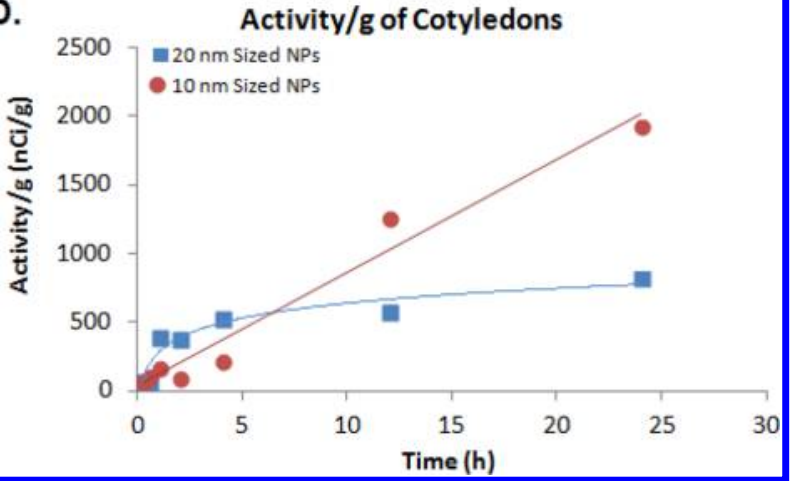

Figure 4. A. Bar graph of $\left[{ }^{64} \mathrm{Cu}\right]-\mathrm{NP}$ uptake in lettuce roots over time $(n=3)$. B. Decay corrected biodistribution averages (nCi/g) plotted over time to display uptake trend in root $(n=3)$. C. Bar graph of $\left[{ }^{64} \mathrm{Cu}\right]-\mathrm{NP}$ uptake in lettuce cotyledons over time $(n=3)$. D. Decay corrected biodistribution averages $(\mathrm{nCi} / \mathrm{g})$ plotted over time to display uptake trend in cotyledons $(n=3)$.

remaining in the lower portion of the root (where it had been submerged) (Figure 2). PET/CT imaging after a $2 \mathrm{~h}$ uptake period showed that the $\left[{ }^{64} \mathrm{Cu}\right]$-NPs moved readily from the root radicle to the cotyledons and matches the same $\left[{ }^{64} \mathrm{Cu}\right]-\mathrm{NP}$ movement observed by autoradiography (Figure 3).

Plotting the biodistribution averages of radioactivity/gram of lettuce $(\mathrm{nCi} / \mathrm{g})$ for both sets of $\left[{ }^{64} \mathrm{Cu}\right]-\mathrm{NPs}(\mathbf{1 0}, \mathbf{1 1})$ demonstrated a size-dependent uptake. The average values continually increased over time for the smaller $\left[{ }^{64} \mathrm{Cu}\right]$-NPs $(10$ $\mathrm{nm}, \mathbf{1 0})$, while the larger $\left[{ }^{64} \mathrm{Cu}\right]-\mathrm{NPs}(20 \mathrm{~nm}, \mathbf{1 1})$ biodistribution levelled off after the initial uptake period of 4 h (Figure 4 (B and D), S6). The initial amount of $\left[{ }^{64} \mathrm{Cu}\right]-\mathrm{NPs}$ in the root was higher for the larger $\left[{ }^{64} \mathrm{Cu}\right]-\mathrm{NPs}(11)$ being around $1.83 \pm 0.11 \mu \mathrm{g} / \mathrm{g}(2065 \mathrm{nCi} / \mathrm{g})$ of lettuce $(0.25 \mathrm{~h})$, while the small $\left[{ }^{64} \mathrm{Cu}\right]-\mathrm{NPs}(10)$ contained $1.50 \pm 0.19 \mu \mathrm{g} / \mathrm{g}$ $(2043 \mathrm{nCi} / \mathrm{g})$. The initial amount per plant at early time points were not much different for either size, but after $24 \mathrm{~h}$ accumulation time, the smaller $\left[{ }^{64} \mathrm{Cu}\right]-\mathrm{NP}$ (10) amount was much higher, being $7.56 \pm 0.85 \mu \mathrm{g} / \mathrm{g}(10276 \mathrm{nCi} / \mathrm{g})$ while the $20 \mathrm{~nm}\left[{ }^{64} \mathrm{Cu}\right]-\mathrm{NP}(11)$ reached a plateau at approximately 5.7 $\mu \mathrm{g} / \mathrm{g}(6369 \mathrm{nCi} / \mathrm{g})$. The larger $\left[{ }^{64} \mathrm{Cu}\right]-\mathrm{NPs}(11)$ had relatively the same uptake over the $1-12 \mathrm{~h}$ time frame with a slightly higher uptake at the $24 \mathrm{~h}$ time point with the same trend for 11 in the cotyledons. The smaller $\left[{ }^{64} \mathrm{Cu}\right]$-NPs $(\mathbf{1 0})$ had relatively the same quantity of NPs from 1 to $4 \mathrm{~h}$ but after $4 \mathrm{~h}$ increased linearly. The biodistribution data show that $>80 \%$ of the $\left[{ }^{64} \mathrm{Cu}\right]$-NPs were contained in the root for both sizes over all time points; $\left[{ }^{64} \mathrm{Cu}\right]-\mathrm{NPs} 10$ showed a range of $4-19 \%$ in the cotyledons and $\left[{ }^{64} \mathrm{Cu}\right]-\mathrm{NPs} 11$ showed $3-14 \%$ in the cotyledons (Figures S6). The $24 \mathrm{~h}$ time point showed the highest $\left[{ }^{64} \mathrm{Cu}\right]-\mathrm{NP}$ uptake as expected with 10 having $6.15 \pm$ $0.63 \mu \mathrm{g} / \mathrm{g}(8350 \mathrm{nCi} / \mathrm{g})$ in the root and $1.42 \pm 0.20 \mu \mathrm{g} / \mathrm{g}$ $(1927 \mathrm{nCi} / \mathrm{g})$ in the cotyledons and 11 with $4.93 \pm 1.03 \mu \mathrm{g} / \mathrm{g}$
$(5553 \mathrm{nCi} / \mathrm{g})$ in the root and $0.73 \pm 0.05 \mu \mathrm{g} / \mathrm{g}(817 \mathrm{nCi} / \mathrm{g})$ in the cotyledons. Interestingly, increasing the concentration (even with higher amounts of radioactivity), had negligible effects on $\left[{ }^{64} \mathrm{Cu}\right]-\mathrm{NPs}$ (10 or 11) uptake and accumulation during a $2 \mathrm{~h}$ period ( $4 \mu \mathrm{g} / \mathrm{g}$ of lettuce)(Figure 5), suggesting a saturable transport or strong bottleneck for movement across the root tissue into the cotyledons.

The biodistribution of radioactivity for each part of the lettuce (root or cotyledons) confirmed that while most the

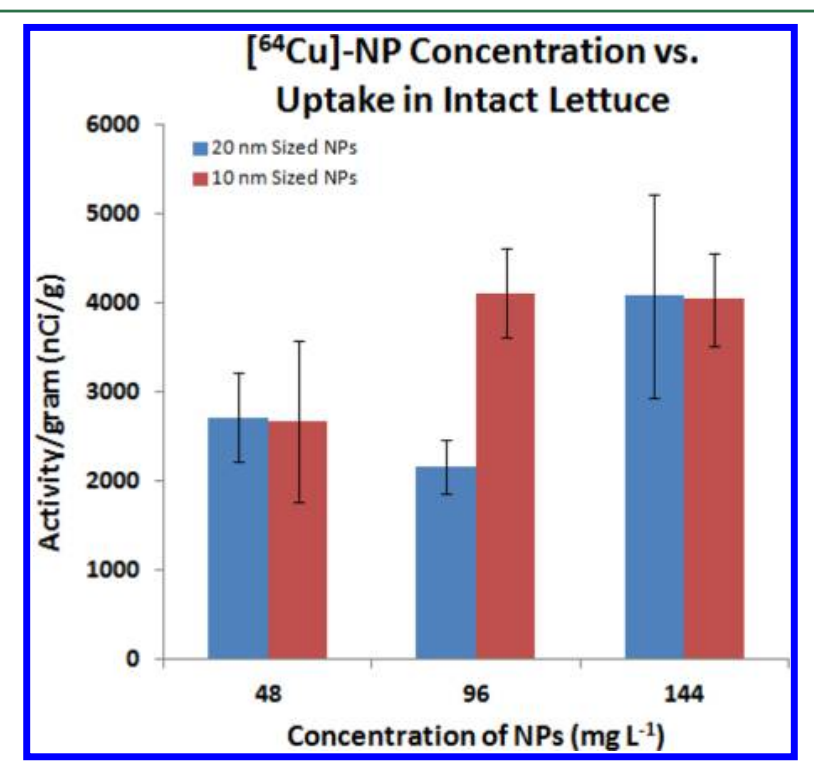

Figure 5. $\left[{ }^{64} \mathrm{Cu}\right]-\mathrm{NP}$ concentration vs uptake in intact lettuce $(n=3)$ at $2 \mathrm{~h}$. 
radioactivity was in the roots (Figures 4 and S6), some of the $\left[{ }^{64} \mathrm{Cu}\right]$-NPs $(10$ and 11) traveled up the root with visible amounts of $\left[{ }^{64} \mathrm{Cu}\right]$-NPs being in the cotyledon apex (Figure 2D). The biodistribution data correlated well with the autoradiography and PET/CT images (Figures 2, 3, S6, and S9).

The autoradiography images (Figures 2, S6, and S9) and observed biodistribution suggest that the $\left[{ }^{64} \mathrm{Cu}\right]$-NPs were intact during transport as control plants exposed to just radioactive isotope $\left[{ }^{64} \mathrm{Cu}\right] \mathrm{CuCl}_{2}(\mathrm{S10})$ exhibited approximately 4-fold higher activity per gram of plant in the cotyledon and 10fold more activity per gram in the root radicle. Furthermore, the autoradiography images of the control lettuce seedlings (and additional control duckweed) appear to have a more uniform uptake throughout the plant that correlated to higher amounts of activity, most notably in the cotyledon (S10). Additional supporting evidence was obtained from the optically tagged NPs containing a covalently bound fluorescence tag, which also showed the same NP-movement from root to the cotyledon further substantiating intact NP transportation through the lettuce seedlings (S1, S8).

Plant Uptake of NPs Correlated Imaging: SEM and TEM. Since most of the radioactivity was contained in the root, additional tests were conducted with SEM to verify that this radioactive signal was coming from NPs inside and not adhered to the outer surface of the root (Figure 6A). Unwashed roots exhibited more radioactivity by both autoradiography and gamma counting compared to roots that had been soaked in detergent and EDTA solution prior to imaging and counting of

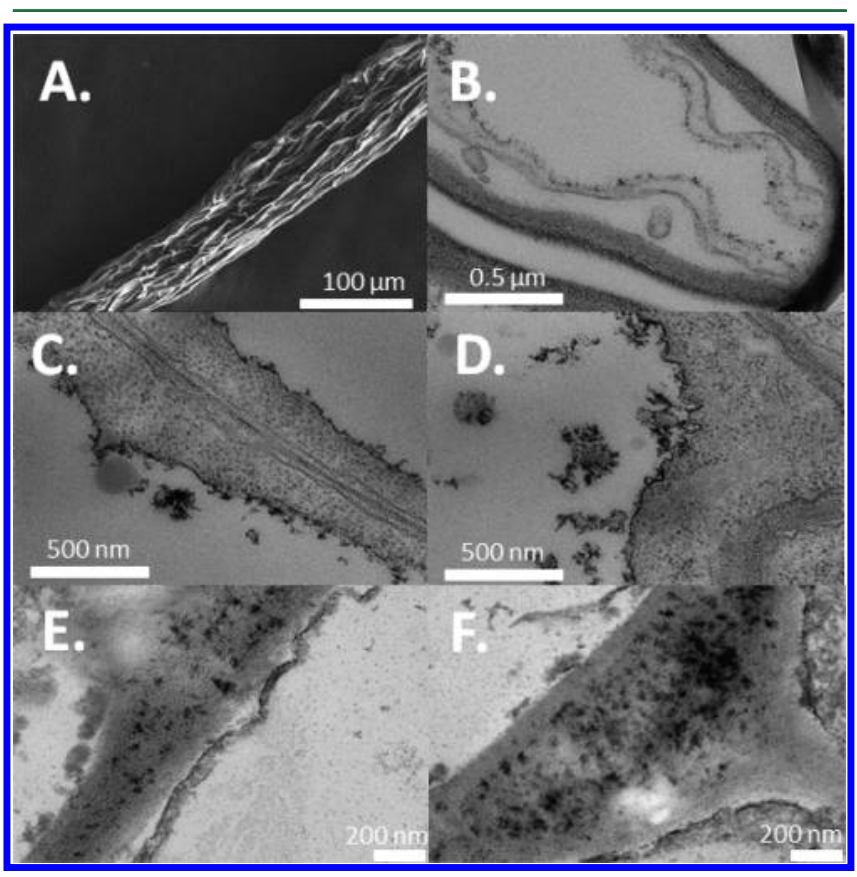

Figure 6. A. Representative SEM image of the lower portion of root exposed to $\left[{ }^{64} \mathrm{Cu}\right]-\mathrm{NP}$ suspension showing no adherence of NPs to the outer surface of the root after washing with EDTA and Triton100X solution. B. Representative TEM image of lettuce not exposed to NPs C. Representative TEM image of lettuce root section after $\left[{ }^{64} \mathrm{Cu}\right]-\mathrm{NP}$ $(10,10 \mathrm{~nm})$ exposure. D. Representative TEM image of lettuce cotyledon section after $\left[{ }^{64} \mathrm{Cu}\right]-\mathrm{NP}(10,10 \mathrm{~nm})$ exposure. E. Representative TEM image of lettuce root section after $\left[{ }^{64} \mathrm{Cu}\right]-\mathrm{NP}$ $(11,20 \mathrm{~nm})$ exposure. F. Representative TEM image of lettuce cotyledon section after $\left[{ }^{64} \mathrm{Cu}\right]-\mathrm{NP}(11,20 \mathrm{~nm})$ exposure. the radioactivity. SEM confirmed that root washing efficiently removed any NPs adhered to the root outer surface (Figure 6A). TEM images of fixed and sectioned lettuce tissue showed the appearance of the $\left[{ }^{64} \mathrm{Cu}\right]-\mathrm{NPs}$ within the plant tissue, indicating intact transport (Figure $6 \mathrm{C}-\mathrm{F}$ ). However, the observed $\left[{ }^{64} \mathrm{Cu}\right]$-NPs appeared smaller than those administered for the $\left[{ }^{64} \mathrm{Cu}\right]$-NPs $(\mathbf{1 1}, 20 \mathrm{~nm})$ but exact size determination was difficult due to NP-aggregation.

\section{DISCUSSION}

To date the uptake, bioaccumulation, biotransformation, and risks of NPs in food crops is not well understood. ${ }^{8}$ Most studies on NP uptake in plants have focused on the effects of NPs on plants, and have not focused on the transport or entry of intactNPs. Several studies concluded that NPs do not gain entry into plants, ${ }^{22,36-38}$ while those that do show NP uptake in plants have found the NP amounts to vary widely between $0.05 \mu \mathrm{g} / \mathrm{g}$ and $38983 \mu \mathrm{g} / \mathrm{g}$ of plant. ${ }^{1,10-16,20,27-30,45}$ In vivo tracking of NP transport in plants has traditionally relied on destructive analytical techniques to quantify NP-uptake and accumulation, requiring mineralization for metal quantification mostly by ICP. ${ }^{14-20}$ These analytical techniques face the challenge of being sensitive enough to reliably measure the small changes in metal concentrations caused by NP-uptake and accumulation within the plant. The extensive range of NP accumulation reported in plants suggests that NP-uptake is dependent on several parameters: (1) quantity of NP administered per plant, (2) plant species, (3) NP-size, (4) NP-composition, and (5) duration of exposure. ${ }^{1,12,14-18,45}$ Further complicating the understanding of NP transport and accumulation in plants are the studies that have observed NP-uptake due to dissolution. ${ }^{14,17-19,33-35}$ Collectively the variations of parameters in every study on NP transport in plants have made direct comparison and accurate conclusions challenging. Thus, it was our goal to develop a noninvasive visualization approach to track and quantify the distribution of intact radiolabeled $\left[{ }^{64} \mathrm{Cu}\right]$-NPs (10 and 11) in lettuce seedlings. Using ${ }^{64} \mathrm{Cu}$ radioactively tagged NPs, we employed a range of complementary noninvasive analytical tools including autoradiography and PET/CT imaging to spatially and temporally visualize and quantify intact-NP uptake and accumulation in plants.

The stability study described demonstrates dissolution of the $\left[{ }^{64} \mathrm{Cu}\right]$-NPs did not occur. Ligand effects on NP mobility within the lettuce was minimized by modification of $\leq 5 \%$ of the $\mathrm{NP}$ surface with $\left[{ }^{64} \mathrm{Cu}\right]$-ADIBO-NOTA (7) as to negligibly change the NP surface properties. No ligand detachment or leaching of ${ }^{64} \mathrm{Cu}$-ion from the NPs within the imaging time frame and at various pHs (S4) was observed, by both HPLC and gamma counting analysis, indicating that the radioactive signal in the lettuce seedlings was due to intact $\left[{ }^{64} \mathrm{Cu}\right]-\mathrm{NPs}$. Additionally, indirect evidence further supported that the observed uptake was from intact $\left[{ }^{64} \mathrm{Cu}\right]-\mathrm{NPs}$ as control lettuce seedlings given only $\left[{ }^{64} \mathrm{Cu}\right] \mathrm{CuCl}_{2}$ had much higher radioactivity with 4-fold higher concentrations in the cotyledons and 10-fold higher concentrations in the root (Table S10). These control plants also had visibly higher amounts of radioactivity in each part of the plant by autoradiography images (S10) suggesting that if the observed radioactivity was due to $\left[{ }^{64} \mathrm{Cu}\right] \mathrm{CuCl}_{2}$, then the uptake should be much higher. Furthermore, the use of covalently bound optical-tagged NPs (S1) also exhibiting high stability and illustrated the same NP movement from the root to the cotyledon (S8). Thus, helping to substantiate that NP-uptake and transport to the cotyledon 
was from intact NPs. TEM-sectioning of the plant tissue also helped to corroborate the presence of NPs within the plant tissue (Figure 6). It should be noted that detection of NPs within plant tissue via TEM is challenging, ${ }^{48}$ but based on our stability studies of the ${ }^{64} \mathrm{Cu}$-radiolabeled NPs along with the short exposure time that the observed uptake was attributed to intact $\left[{ }^{64} \mathrm{Cu}\right]-\mathrm{NP}$ transport through the roots and into the cotyledons.

This study has shown that NPs were transported intact into plants and can be tracked noninvasively using a radioactive tag for in vivo imaging by autoradiography and PET/CT and quantification using a gamma counter. This method allows for a highly sensitive method capable of quantifying NP amounts in an individual seedling, a level that would be challenging by the traditional ICP quantification. ${ }^{1,22,23,26}$ We found that $\left[{ }^{64} \mathrm{Cu}\right]$ NP accumulation in lettuce was size-dependent indicated by the larger $\left[{ }^{64} \mathrm{Cu}\right]-\mathrm{NPs} \mathbf{1 1}$ reaching a plateau at a given concentration, while the smaller $\left[{ }^{64} \mathrm{Cu}\right]-\mathrm{NPs} \mathbf{1 0}$ increased continually over time (Figure 4). Our study indicates that both sets of $\left[{ }^{64} \mathrm{Cu}\right]$-NPs travel intact from the root radicle to the cotyledon (Figures 2 and 3) with the smaller $10 \mathrm{~nm}\left[{ }^{64} \mathrm{Cu}\right]-\mathrm{NP}$ (10) having a maximum accumulation of $7.56 \pm 0.85 \mu \mathrm{g} / \mathrm{g}$ in the whole plant, $6.15 \pm 0.63 \mu \mathrm{g} / \mathrm{g}$ in the root, and $1.42 \pm 0.20$ $\mu \mathrm{g} / \mathrm{g}$ in the cotyledons (Figure 4 and Table S6). The larger 20 $\mathrm{nm}\left[{ }^{64} \mathrm{Cu}\right]-\mathrm{NPs}(11)$ had an accumulation that reached a maximum of $5.66 \pm 1.08 \mu \mathrm{g} / \mathrm{g}$ in the whole plant, $4.93 \pm 1.03$ $\mu \mathrm{g} / \mathrm{g}$ in the root, and $0.73 \pm 0.05 \mu \mathrm{g} / \mathrm{g}$ in the cotyledon (Figure 4 and Table S6). It is clear from our imaging data, both by autoradiography and PET/CT (Figures 2 and 3) that the $\left[{ }^{64} \mathrm{Cu}\right]-\mathrm{NPs}$ are transported intact from the root to the cotyledons and are present in the lettuce tissue by TEM (Figure 6). However, different accumulation patterns for the cotyledons were observed for the two different sized $\left[{ }^{64} \mathrm{Cu}\right]$ NPs (10 and 11), while the root and whole plant were similar (Figures 4 and S6). Most of the accumulation for the larger $\left[{ }^{64} \mathrm{Cu}\right]-\mathrm{NPs}(11,20 \mathrm{~nm})$ was within the first hour, where cotyledon NP amounts were $\sim 0.35 \pm 0.15 \mu \mathrm{g} / \mathrm{g}$ with the only significant increase after $1 \mathrm{~h}$ between the 12 and $24 \mathrm{~h}$ time point in which accumulation plateaued at around $\sim 0.7 \mu \mathrm{g} / \mathrm{g}(p-$ value $=0.004$, Student's $t$ test at 95\% confidence level) (Figures 4 and S6). The larger $\left[{ }^{64} \mathrm{Cu}\right]-\mathrm{NPs}(11,20 \mathrm{~nm})$ also had higher accumulation than the $\left[{ }^{64} \mathrm{Cu}\right]-\mathrm{NPs}(10,10 \mathrm{~nm})$ at the early time points up to the $4 \mathrm{~h}$ time period. The smaller $\left[{ }^{64} \mathrm{Cu}\right]-\mathrm{NPs}$ $(10,10 \mathrm{~nm})$ had $\sim 8.8$ fold increase in cotyledon accumulation from the $4 \mathrm{~h}$ time point to the $24 \mathrm{~h}$ time point with an increase of $\sim 1.6$ fold between 12 and $24 \mathrm{~h}$ time period (Figure 4) appearing to have a linear increase in absorption over time. The differences in cotyledon accumulation between the two sized $\left[{ }^{64} \mathrm{Cu}\right]$-NPs maybe linked to NP size effects on the lettuce hydraulic conductivity. Our work suggests that $\left[{ }^{64} \mathrm{Cu}\right]-\mathrm{NPs}$ (11) around $20 \mathrm{~nm}$ in size appear to clog root cortical cell walls, or pit membrane (or some other bottleneck along the uptake and transport pathway) preventing further uptake, explaining why 11 reaches a plateau, while the smaller $\left[{ }^{64} \mathrm{Cu}\right]$ NPs (10) continued to increase in amount over time. Initial studies with duckweed also illustrated $\left[{ }^{64} \mathrm{Cu}\right]-\mathrm{NP}$ accumulation in regions of growth and at the node and apex of the cotyledons (Figure S7), suggesting that $\left[{ }^{64} \mathrm{Cu}\right]-\mathrm{NP}$ transport to the cotyledons could occur via the phloem. The TEM images (Figure 6) further shows the appearance of intact NPs in the lettuce tissue within the expected size range for the $\left[{ }^{64} \mathrm{Cu}\right]-\mathrm{NPs}$ $(10,10 \mathrm{~nm})$ (Figure 6C, D), but $\left[{ }^{64} \mathrm{Cu}\right]-\mathrm{NPs}(11,20 \mathrm{~nm})$ had a size that appeared smaller than those administered; suggesting that the plant may filter larger NPs and has a size-threshold for uptake (Figure 6E, F), which may also explain the clogging phenomenon. ${ }^{27,28,48}$ In summary, the combined analysis of the imaging by autoradiography and PET/CT (Figures 2 and 3) and TEM (Figure 6) suggested that both sized $\left[{ }^{64} \mathrm{Cu}\right]-\mathrm{NPs}$ are transported intact from the root to the cotyledons.

The $\left[{ }^{64} \mathrm{Cu}\right]$-NP-uptake and accumulation amounts observed within lettuce seedlings were reasonable and comparable to others reports in the literature, reaching the same general conclusions that NP transport and accumulation in plants is species and size dependent. $1,12,16,18,21,23,30$ Smaller NPs have been demonstrated to have higher accumulation in plants than larger NPs. For example, Ni-NPs (1, 3, and $9 \mathrm{~nm})$ had very high NP uptake ranging from $\sim 13200-38983 \mu \mathrm{g} / \mathrm{g}$ in mesquite. ${ }^{45}$ The amount found in the leaves varied from 400 to $803 \mu \mathrm{g} / \mathrm{g}$ of mesquite with most the NPs remaining in the roots ranging from 12835 to $38183 \mu \mathrm{g} / \mathrm{g}$. ${ }^{45}$ Another study using small $\mathrm{CeO}_{2}$-NPs $(7 \mathrm{~nm})$ exhibited NP accumulation ranging from 300 to $6000 \mu \mathrm{g} / \mathrm{g}$ of plant (corn, soy bean, cucumber, tomato, and alfalfa) and indicated that NP accumulation was plant species dependent. ${ }^{10} \mathrm{NP}$ sizes above active transport ranging from 14 to $40 \mathrm{~nm}$ had a large variation in uptake ranging from 0.25 to $3750 \mu \mathrm{g} / \mathrm{g}$ of plant, but typically had accumulation ranging from $\sim 1-1100 \mu \mathrm{g} / \mathrm{g}$ of plant again with the majority of the NPs contained within the root and with $0.5-183 \mu \mathrm{g} / \mathrm{g}$ in the leaves. ${ }^{1,15,16,20,27,29} \mathrm{NPs}(50 \mathrm{~nm})$, had accumulation in mung bean of $8 \mu \mathrm{g} / \mathrm{g}$ and in wheat of $32 \mu \mathrm{g} /$ g. ${ }^{32}$ When comparing the accumulation of two similarly sized $\mathrm{TiO}_{2}$-NPs of different crystalline structure [22 $\mathrm{nm}$ (rutile) and $25 \mathrm{~nm}$ (anatase)] in wheat different accumulation amounts were observed, suggesting size was not the only limiting factor for transportation into a plant. ${ }^{1}$

In another study using radioactive NPs, Zhang et al. ${ }^{12}$ generated ${ }^{141} \mathrm{Ce}$ by neutron bombardment of $\mathrm{CeO}_{2} \mathrm{NPs}$ synthesized via a precipitation method. The fabrication of $\left[{ }^{141} \mathrm{Ce}\right] \mathrm{CeO}_{2}-\mathrm{NPs}$ could make controlling the size distribution very difficult and the exact size of the radioactive $\left[{ }^{141} \mathrm{Ce}\right] \mathrm{CeO}_{2}$ NPs was never determined. In addition, free radioactive ${ }^{141} \mathrm{Ce}-$ metal could dissolute and be transported into the plant, making it appear as if the intact-NPs were in the plant because possible leaching of radioactivity was not explored. We aimed to avoid complications of NP-fabrication in which the exact size distribution during the study could not be determined and to improve upon prior radiolabeling methods, which gave low specific activity (radioactivity/mass of the NP material) of 2.7 $\mu \mathrm{Ci} / \mathrm{mg}$ of NP. ${ }^{13}$ We were able to generate stable radioactive $\left[{ }^{64} \mathrm{Cu}\right]-\mathrm{NPs}$ with high radiochemical purity $(>99 \%)$ and a specific activity of $2.2 \mathrm{mCi} / \mathrm{mg}$ of $\mathrm{NP}$ with a tight size distribution (S5). Zhang et al.'s work also demonstrated a concentration and size dependence of the $\left[{ }^{141} \mathrm{Ce}\right] \mathrm{CeO}_{2}-\mathrm{NPs}$ on plant accumulation in cucumber. ${ }^{12}$ At the lower concentration $\left(20 \mathrm{mg} \mathrm{L}^{-1}\right)\left[{ }^{141} \mathrm{Ce}\right] \mathrm{CeO}_{2}-\mathrm{NPs}$ roots accumulation was $\sim 370$ $\mu \mathrm{g} / \mathrm{g}$ for the small $7 \mathrm{~nm}-\mathrm{NPs}$ and $\sim 70 \mu \mathrm{g} / \mathrm{g}$ for the $25 \mathrm{~nm}-\mathrm{NPs}$. At the highest concentration $\left(200 \mathrm{mg} \mathrm{L}^{-1}\right),\left[{ }^{141} \mathrm{Ce}\right] \mathrm{CeO}_{2}-\mathrm{NP}$ uptake was much higher for both sizes being $\sim 700 \mu \mathrm{g} / \mathrm{g}$ and $\sim 500 \mu \mathrm{g} / \mathrm{g}$ of cucumber (7 and $25 \mathrm{~nm}$ NPs, respectively). ${ }^{12}$ In agreement with our study was that smaller NPs have higher accumulation.

Zhang et al. also noted that accumulation in the leaves was less affected by the size of the $\left[{ }^{141} \mathrm{Ce}\right] \mathrm{CeO}_{2}-\mathrm{NPs}$ with the average uptake in the leaves for the $7 \mathrm{~nm}-\mathrm{NP}$ being $0.4 \mu \mathrm{g} / \mathrm{g}$ and $0.18 \mu \mathrm{g} / \mathrm{g}$ for the $25 \mathrm{~nm}-\mathrm{NPs}{ }^{12}$ We observed similar amounts in lettuce cotyledons for the $24 \mathrm{~h}$ uptake period with 
the accumulation of 10 being $1.4 \mu \mathrm{g} / \mathrm{g}$ and 11 being $0.7 \mu \mathrm{g} / \mathrm{g}$. However, the observed accumulation in the cotyledons for $\left[{ }^{64} \mathrm{Cu}\right]$-NPs was lower than the amounts observed by Zhang et al. $^{12}$ at the very early time points and it was not until the $4 \mathrm{~h}$ time point when accumulation amounts in the cotyledons started becoming larger than $0.4 \mu \mathrm{g} / \mathrm{g}$ of lettuce. These uptake differences may be attributed to the use of a different species and/or the NP solution administered had 2.4-times higher concentration (48 $\mathrm{mg} \mathrm{L}^{-1}$ ). Autoradiography images showed $\left[{ }^{141} \mathrm{Ce}\right] \mathrm{CeO}_{2}$-NPs movement to the leaves, implying that once NPs entered into the vascular cylinder, they move along with water flow. This was in good agreement with our study. In contrast, we saw no concentration dependence for either sized $\left[{ }^{64} \mathrm{Cu}\right]-\mathrm{NP}(10$ or 11$)$ using 48,96 , and $144 \mathrm{mg} \mathrm{L}^{-1}$ over a $2 \mathrm{~h}$ period with approximately the same accumulation amount at all concentrations ( $\sim 4 \mu \mathrm{g} / \mathrm{g}$ of lettuce) (Figure 5). Similarly, another study using CuO-NPs $(20-40 \mathrm{~nm}$ ) administered two concentrations $10 \mathrm{mg} \mathrm{L}^{-1}$ and $100 \mathrm{mg} \mathrm{L}^{-1}$ for a period of 14 days in maize also observed no concentration dependence. ${ }^{14}$

The use of NPs tagged with radioactivity and tracked by autoradiography and PET/CT has provided a noninvasive analytical tool to spatially visualize and quantify NP uptake and accumulation in plants. We investigated the fate of $\left[{ }^{64} \mathrm{Cu}\right]-\mathrm{NP}$ transport into plants at the largely unexplored early time points, which would prevent dissolution events. Stability studies concluded that the $\left[{ }^{64} \mathrm{Cu}\right]-\mathrm{NPs}$ were stable during the imaging and quantification time frame from 0.25 to $24 \mathrm{~h}$ resulting in intact NP-transport into lettuce seedlings. We further demonstrated that the transport of $\left[{ }^{64} \mathrm{Cu}\right]-\mathrm{NPs}$ into lettuce was not concentration dependent but was size dependent with the $20 \mathrm{~nm}\left[{ }^{64} \mathrm{Cu}\right]-\mathrm{NPs}$ reaching a plateau with accumulation at $\sim 5.7 \mu \mathrm{g} / \mathrm{g}$ of lettuce and the smaller $10 \mathrm{~nm}$ NPs accumulation increasing linearly with the maximum amount at $24 \mathrm{~h}$ being $\sim 7.6 \mu \mathrm{g} / \mathrm{g}$ of lettuce. TEM images further substantiated the intact transport of NPs into plants. With the numerous factors that may dictate NP uptake and accumulation, further studies are warranted to fully understand the molecular mechanism of NP transport into plants.

\section{ASSOCIATED CONTENT}

\section{S Supporting Information}

The Supporting Information is available free of charge on the ACS Publications website at DOI: 10.1021/acs.est.7b03333.

Details on synthetic compound characterization, click reaction, radiolabeling of NPs, NP characterization, NP stability data, TEM, SEM, and plant section data (PDF)

\section{AUTHOR INFORMATION}

\section{Corresponding Author}

*Phone: 1-916-734-5536; fax: 1-916-734-7572 (J.L.S.).

\section{ORCID}

Ryan A. Davis: 0000-0002-0638-870X

\section{Notes}

The authors declare no competing financial interest.

\section{ACKNOWLEDGMENTS}

This work was supported in part by the Office of Science, United States Department of Energy Grant: DE-SC0008385. Additional support is provided by the National Institute of Food and Agriculture, U.S. Department of Agriculture, under grant award number: 2013-67017-21211. We would also like to acknowledge Patricia E. Kysar, Staff Research Associate, Medical Science Electron Microscopy Lab, University of California-Davis and Dr. Fei Guo, Electron Microscopy Facility Director, Electron Imaging Facility, University of California-Davis for SEM and TEM help.

\section{REFERENCES}

(1) Larue, C.; et al. Accumulation, translocation and impact of $\mathrm{TiO}_{2}$ nanoparticles in wheat (Triticum aestivum spp.): Influence of diameter and crystal phase. Sci. Total Environ. 2012, 431, 197-208.

(2) Rodrigues, S. M. T. T; Duarte, A. C.; Pereira, E.; Koopmans, G. F.; Romkens, P. F. A. M.; Trindade, T. A framework to measure the availability of engineered nanoparticles in soils: Trends in soil tests and analytical tools. TrAC, Trends Anal. Chem. 2016, 75, 129-140.

(3) Aguilera, J. M. Where is the nano in our foods? J. Agric. Food Chem. 2014, 62 (41), 9953-9956.

(4) Magnuson, B. A.; Jonaitis, T. S.; Card, J. W. A brief review of the occurrence, use, and safety of food-related nanomaterials. J. Food Sci. 2011, 76 (6), R126-R133.

(5) Mueller, N. C.; Nowack, B. Exposure modeling of engineered nanoparticles in the environment. Environ. Sci. Technol. 2008, 42 (12), 4447-4453.

(6) Llop, J.; et al. Uptake, biological fate, and toxicity of metal oxide nanoparticles. Part. Part. Sust. Charact. 2014, 31 (1), 24-35.

(7) $\mathrm{Ma}, \mathrm{X}$; et al. Interactions between engineered nanoparticles (ENPs) and plants: Phytotoxicity, uptake and accumulation. Sci. Total Environ. 2010, 408 (16), 3053-3061.

(8) Rico, C. M.; et al. Interaction of nanoparticles with edible plants and their possible implications in the food chain. J. Agric. Food Chem. 2011, 59 (8), 3485-3498.

(9) Gardea-Torresdey, J. L.; Rico, C. M.; White, J. C. Trophic transfer, transformation, and impact of engineered nanomaterials in terrestrial environments. Environ. Sci. Technol. 2014, 48 (5), 25262540.

(10) López-Moreno, M. L.; et al. Evidence of the differential biotransformation and genotoxicity of $\mathrm{ZnO}$ and $\mathrm{CeO}_{2}$ nanoparticles on soybean (Glycine max) plants. Environ. Sci. Technol. 2010, 44 (19), $7315-7320$.

(11) Baek, Y.-W.; An, Y.-J. Microbial toxicity of metal oxide nanoparticles $\left(\mathrm{CuO}, \mathrm{NiO}, \mathrm{ZnO}\right.$, and $\left.\mathrm{Sb}_{2} \mathrm{O}_{3}\right)$ to Escherichia coli, Bacillus subtilis, and Streptococcus aureus. Sci. Total Environ. 2011, 409 (8), 1603-1608.

(12) Zhang, Z.; et al. Uptake and distribution of ceria nanoparticles in cucumber plants. Metallomics 2011, 3 (8), 816-822.

(13) Stockhofe, K.; Postema, J. M.; Schieferstein, H.; Ross, T. L. Radiolabeling of nanoparticles and polymers for PET imaging. Pharmaceuticals 2014, 7, 392-418.

(14) Wang, Z.; et al. Xylem- and phloem-based transport of $\mathrm{CuO}$ nanoparticles in maize (Zea mays L.). Environ. Sci. Technol. 2012, 46 (8), 4434-4441.

(15) Vittori Antisari, L.; et al. Uptake and translocation of metals and nutrients in tomato grown in soil polluted with metal oxide $\left(\mathrm{CeO}_{2}\right.$, $\left.\mathrm{Fe}_{3} \mathrm{O}_{4}, \mathrm{SnO}_{2}, \mathrm{TiO}_{2}\right)$ or metallic $(\mathrm{Ag}, \mathrm{Co}, \mathrm{Ni})$ engineered nanoparticles. Environ. Sci. Pollut. Res. 2015, 22 (3), 1841-1853.

(16) Zhang, W.; et al. Uptake and accumulation of bulk and nanosized cerium oxide particles and ionic cerium by radish (Raphanus sativus L.). I. Agric. Food Chem. 2015, 63 (2), 382-390.

(17) Cui, D.; et al. Effect of cerium oxide nanoparticles on asparagus lettuce cultured in an agar medium. Environ. Sci.: Nano 2014, 1 (5), 459-465.

(18) Schwabe, F.; et al. Dissolved Cerium contributes to uptake of Ce in presence of differently sized $\mathrm{CeO}_{2}$-nanoparticles by three crop plants. Metallomics 2015, 7 (3), 466-477.

(19) Ma, Y.; et al. Phytotoxicity and biotransformation of $\mathrm{La}_{2} \mathrm{O}_{3}$ nanoparticles in a terrestrial plant cucumber (Cucumis sativus). Nanotoxicology 2011, 5 (4), 743-753. 
(20) Wang, Q.; et al. The impact of cerium oxide nanoparticles on tomato (Solanum lycopersicum L.) and its implications for food safety. Metallomics 2012, 4 (10), 1105-1112.

(21) Miralles, P.; Church, T. L.; Harris, A. T. Toxicity, uptake, and translocation of engineered nanomaterials in vascular plants. Environ. Sci. Technol. 2012, 46 (17), 9224-9239.

(22) Wang, $\mathrm{H}$.; et al. Physiological effects of magnetite $\left(\mathrm{Fe}_{3} \mathrm{O}_{4}\right)$ nanoparticles on perennial ryegrass (Lolium perenne L.) and pumpkin (Cucurbita mixta) plants. Nanotoxicology 2011, 5 (1), 30-42.

(23) López-Moreno, M. L.; et al. X-ray absorption spectroscopy (XAS) corroboration of the uptake and storage of $\mathrm{CeO}_{2}$ nanoparticles and assessment of their differential toxicity in four edible plant species. L. Agric. Food Chem. 2010, 58 (6), 3689-3693.

(24) Nordmann, J.; et al. In vivo analysis of the size- and timedependent uptake of $\mathrm{NaYF}_{4}: \mathrm{Yb}, \mathrm{Er}$ upconversion nanocrystals by pumpkin seedlings. I. Mater. Chem. B 2015, 3 (1), 144-150.

(25) Hischemöller, A.; et al. Imaging of the uptake of upconversion

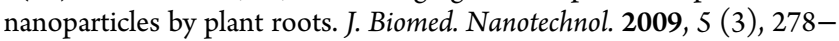
284.

(26) $\mathrm{He}, \mathrm{X}$.; et al. Quantifying and imaging engineered nanomaterials in vivo: Challenges and techniques. Small 2013, 9 (9-10), 14821491

(27) Lin, D.; Xing, B. Root uptake and phytotoxicity of $\mathrm{ZnO}$ nanoparticles. Environ. Sci. Technol. 2008, 42 (15), 5580-5585.

(28) Zhu, H.; et al. Uptake, translocation, and accumulation of manufactured iron oxide nanoparticles by pumpkin plants. J. Environ. Monit. 2008, 10 (6), 713-717.

(29) Zhao, L.; et al. Monitoring the environmental effects of $\mathrm{CeO}_{2}$ and $\mathrm{ZnO}$ nanoparticles through the life cycle of corn (Zea mays) plants and in situ $\mu$-XRF mapping of nutrients in kernels. Environ. Sci. Technol. 2015, 49 (5), 2921-2928.

(30) Stampoulis, D.; Sinha, S. K.; White, J. C. Assay-dependent phytotoxicity of nanoparticles to plants. Environ. Sci. Technol. 2009, 43 (24), 9473-9479.

(31) Lin, S.; et al. Uptake, translocation, and transmission of carbon nanomaterials in rice plants. Small 2009, 5 (10), 1128-1132.

(32) Lee, W.-M.; et al. Toxicity and bioavailability of copper nanoparticles to the terrestrial plants mung bean (Phaseolus radiatus) and wheat (Triticum aestivum): Plant agar test for water-insoluble nanoparticles. Environ. Toxicol. Chem. 2008, 27 (9), 1915-1921.

(33) Koo, Y.; et al. Fluorescence reports intact quantum dot uptake into roots and translocation to cotyledons of Arabidopsis thaliana and subsequent ingestion by insect herbivores. Environ. Sci. Technol. 2015, 49 (1), 626-632.

(34) Ma, Y.; et al. Where does the transformation of precipitated ceria nanoparticles in hydroponic plants take place? Environ. Sci. Technol. 2015, 49 (17), 10667-10674.

(35) Zhang, P.; et al. Species-specific toxicity of ceria nanoparticles to Lactuca plants. Nanotoxicology 2015, 9 (1), 1-8.

(36) Doshi, R.; et al. Nano-aluminum: Transport through sand columns and environmental effects on plants and soil communities. Environ. Res. 2008, 106 (3), 296-303.

(37) Asli, S.; Neumann, P. M. Colloidal suspensions of clay or titanium dioxide nanoparticles can inhibit cotyledon growth and transpiration via physical effects on root water transport. Plant, Cell Environ. 2009, 32 (5), 577-584.

(38) Birbaum, K.; et al. No evidence for cerium dioxide nanoparticle translocation in maize plants. Environ. Sci. Technol. 2010, 44 (22), $8718-8723$.

(39) Gardea-Torresdey, J. L.; et al. Formation and growth of $\mathrm{Au}$ nanoparticles inside live alfalfa plants. Nano Lett. 2002, 2 (4), 397401.

(40) Gardea-Torresdey, J. L.; et al. Alfalfa sprouts: A natural source for the synthesis of silver nanoparticles. Langmuir 2003, 19 (4), 13571361.

(41) Bali, R.; Siegele, R.; Harris, A. T. Biogenic Pt uptake and nanoparticle formation in Medicago sativa and Brassica juncea. $J$. Nanopart. Res. 2010, 12 (8), 3087-3095.
(42) Harris, A. T.; Bali, R. On the formation and extent of uptake of silver nanoparticles by live plants. L.Nanopart. Res. 2008, 10 (4), 691695.

(43) Haverkamp, R. G.; Marshall, A. T. The mechanism of metal nanoparticle formation in plants: Limits on accumulation. J. Nanopart. Res. 2009, 11 (6), 1453-1463.

(44) Wang, Y.; et al. Naturally occurring nanoparticles from Arthrobotrys oligospora as a potential immunostimulatory and antitumor agent. Adv. Funct. Mater. 2013, 23 (17), 2175-2184.

(45) Parsons, J. G.; et al. Toxicity and biotransformation of uncoated and coated nickel hydroxide nanoparticles on mesquite plants. Environ. Toxicol. Chem. 2010, 29 (5), 1146-1154.

(46) Kuzmin, A.; et al. Surface functionalization using catalyst-free azide-alkyne cycloaddition. Bioconiugate Chem. 2010, 21 (11), 20762085.

(47) Carpenter, R. D.; Hausner, S. H.; Sutcliffe, J. L. Copper-free click for PET: Rapid 1,3-dipolar cycloadditions with a fluorine-18 cyclooctyne. ACS Med. Chem. Lett. 2011, 2 (12), 885-889.

(48) Taylor, A. F.; Rylott, E. C.; Anderson, C. W. N.; Bruce, N. C. Investigating the toxicity, uptake, nanoparticle formation and genetic response of plants to gold. PLoS One 2014, 9 (4), e93793. 


\section{Supporting Information}

\section{In vivo Tracking of Copper-64 Radiolabeled Nanoparticles in Lactuca sativa}

Ryan A. Davis, ${ }^{1,2}$ Devin A. Rippner, ${ }^{3}$ Sven H. Hausner, ${ }^{1,2}$ Sanjai J. Parikh, ${ }^{3}$ Andrew J. McElrone, ${ }^{4}$ and Julie L. Sutcliffe $e^{1,2,5,6^{*}}$

1. Department of Internal Medicine, Division of Hematology \& Oncology, 2. Radiochemistry Research and Training Facility, 3. Department of Land, Air and Water Resources, 4. USDA-ARS, Department of Viticulture and Enology,5. Department of Biomedical Engineering, and 6. Center for Molecular and Genomic Imaging, University of California, Davis USA 2921 Stockton Blvd. Sacramento, CA 95817

Email: jlsutcliffe@ucdavis.edu

\section{Contents}

Title

Page

S1. Synthesis of optically labeled NPs

Figure S1. Reaction Scheme of optically labeled NPS

S2. Characterization of ADIBO-NOTA (6)

Figure S2. Structure of ADIBO-NOTA (6)

Figure S2a. HPLC-Chromatogram of ADIBO-NOTA (6) S4

Figure S2b. ESI-MS of ADIBO-NOTA (6) S4

Figure S2c. HPLC-Chromatogram of CU-ADIBO-NOTA cold standard S5

Figure S2d. ESI-MS of Cu-ADIBO-NOTA cold standard

S3. Characterization of ${ }^{64} \mathrm{Cu}$-radiolabeled ADIBO-NOTA (7) S6

Figure S3. Structure of $\left[{ }^{64} \mathrm{Cu}\right]-\mathrm{ADIBO}-\mathrm{NOTA}(7) \quad \mathrm{S} 6$

Figure S3a. HPLC-Chromatogram of $\left.\left[{ }^{64} \mathrm{Cu}\right]-\mathrm{ADIBO}-\mathrm{NOTA}(7) \quad \mathrm{S}\right)$

Figure S3b. HPLC-Chromatogram of 7 spiked with cold standard $\quad$ S7 
Figure S3c. HPLC-Chromatogram of EDTA challenged spiked 7

Figure S3d. iTLC of $\left[{ }^{64} \mathrm{Cu}\right]-A D I B O-N O T A(7)$

Figure S4. Structure of $\left[{ }^{64} \mathrm{Cu}\right]-\mathrm{NPs} \quad \mathrm{S} 8$

Figure S4a. Representative HPLC-Chromatogram of $\left[{ }^{64} \mathrm{Cu}\right]-\mathrm{NPs}$ at $\mathrm{pH}-5.0 \quad \mathrm{S9}$

Figure S4b. Representative HPLC-Chromatogram $24 \mathrm{~h}$ after exposure $\quad$ S9 to lettuce seedling

$\begin{array}{ll}\text { S5. Nanoparticle size/colloidal stability characterization } & \text { S10 }\end{array}$

Table S5. Table of NP-size summary (DSL and TEM) and zeta-potential data S10

Figure S5. TEM images and size distribution graph of NPs 8 and $9 \quad$ S10

Figure S5a. TEM images of $\left[{ }^{64} \mathrm{Cu}\right]-N P s \mathbf{1 0}$ and $\mathbf{1 1} \quad$ S11

S6. Summary of biodistribution data in lettuce seedling S11

Table S6. Summary of biodistribution data in lettuce seedling S11

Figure S6. Biodistribution in intact lettuce seedling over time S12

$\begin{array}{ll}\text { S7. Autoradiography imaging of duckweed } & \text { S12 }\end{array}$

Figure S7. Autoradiography images of duckweed $\quad$ S12

S8. Optical image of uptake of dye-labeled NPs in lettuce seedling S13

Figure S8. Uptake of sulforhodamine-labeled NPs (14) in lettuce seedling S13

$\begin{array}{lr}\text { S9. Additional autoradiography images } & \text { S14 }\end{array}$

Figure S9. Additional autoradiography images showing bends in root $\quad$ S14 containing areas of higher radioactivity

S10. Autoradiography image of plants given $\left[{ }^{64} \mathrm{Cu}\right] \mathrm{CuCl}_{2}$

Figure S10. Autoradiography image of lettuce seedling given $\left[{ }^{64} \mathrm{Cu}\right] \mathrm{CuCl}_{2} \quad \mathrm{~S} 15$

Table S10. Biodistribution data for lettuce seedling given $\left[{ }^{64} \mathrm{Cu}\right] \mathrm{CuCl}_{2} \quad \mathrm{~S} 15$

Figure S10a. Autoradiography image of duckweed given $\left[{ }^{64} \mathrm{Cu}\right] \mathrm{CuCl}_{2} \quad \mathrm{~S} 15$ 


\section{S1. Synthesis of optically labeled NPs.}

Each NP 8 and $9\left(50 \mu \mathrm{L}\right.$ of $5 \mathrm{mg} / \mathrm{mL}$ solution) was reacted with ADIBO-PEG $_{4}$-SulfoRhodamine (JenaBiosciences) (12) (145 $\mu \mathrm{L}$, of a $1 \mathrm{mg} / \mathrm{mL}$ solution in di-water) for 30 minutes to give $\mathbf{1 3}$ and $\mathbf{1 4}$. NPs (13 and 14) were diluted with $105 \mu \mathrm{L}$ di-water to a total volume of $300 \mu \mathrm{L}$ each and then purified using a P6-gel size exclusion spin column (Bio-Rad). NPs $\mathbf{1 3}$ and $\mathbf{1 4}$ were filtered out using membrane filters (40,000 molecular weight cut off) and analyzed by HPLC at the $24 \mathrm{~h}$ time point. Filtration of the optically tagged NPs gave a clear filtrate void of any color and upon HPLC analysis showed no UV peak, indicating stability.

Figure S1. Reaction Scheme of optically labeled NPs.

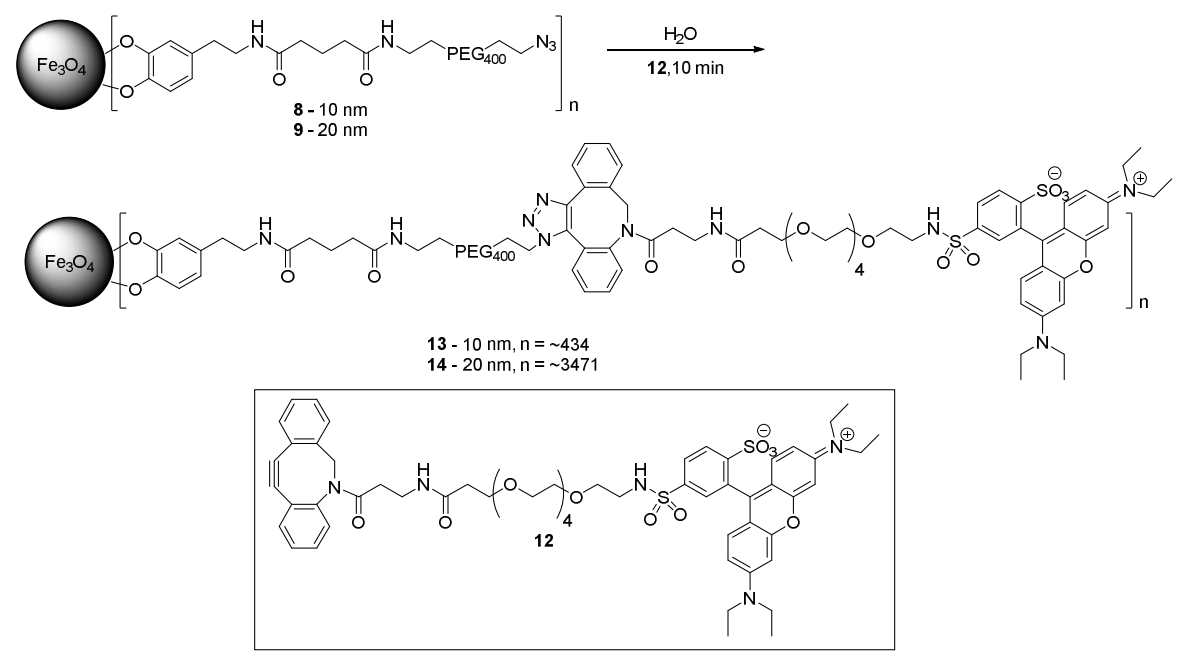

S2. Characterization of ADIBO-NOTA (6)

Figure S2. Structure of ADIBO-NOTA (6)

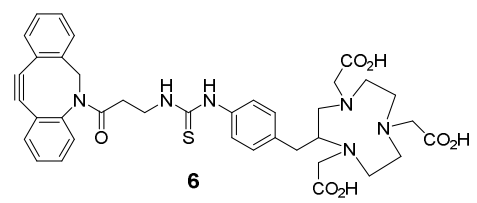


Figure S2a. HPLC-Chromatogram of ADIBO-NOTA (6)

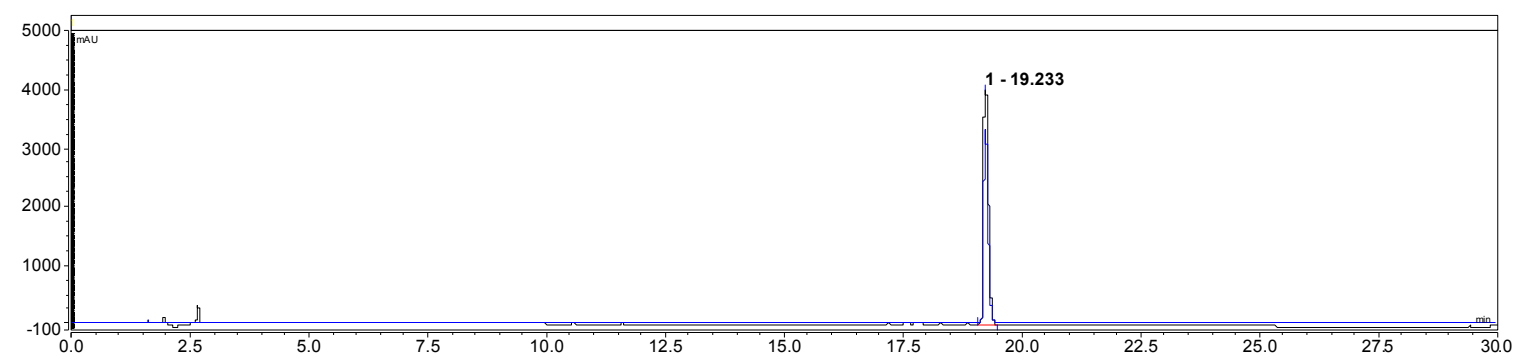

HPLC-Chromatogram: UV absorbance: $220 \mathrm{~nm}$ (black) and $254 \mathrm{~nm}$ (blue). Retention time: 19.23 min.

Figure S2b. ESI-MS of ADIBO-NOTA (6)

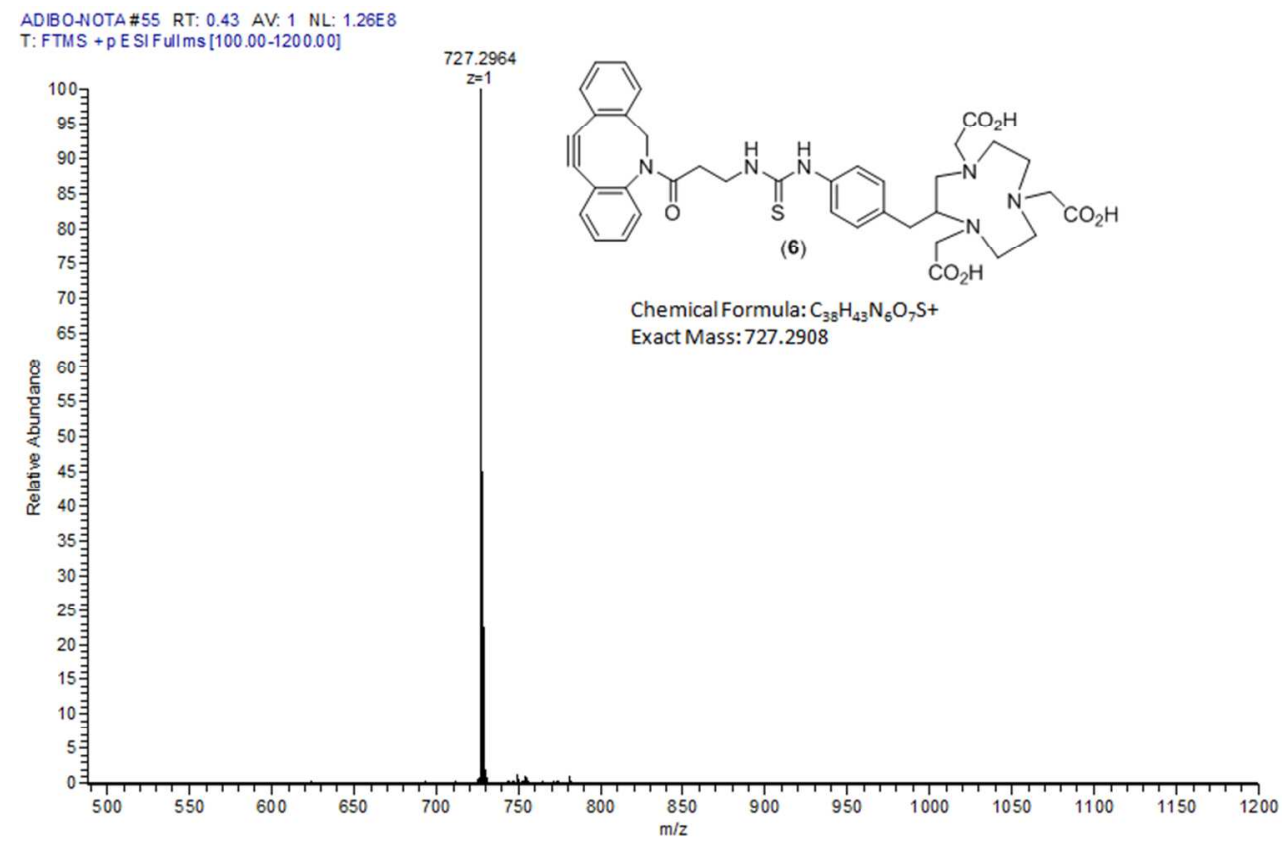

High Resolution Mass Spectrometry: (HRMS)(ESI-MS) m/z: [M+H] $]^{+}$calc'd for $\mathrm{C}_{38} \mathrm{H}_{43} \mathrm{~N}_{6} \mathrm{O}_{7} \mathrm{~S}, 727.2908$; found 727.2964 . 
Figure S2c. HPLC-Chromatogram of Cu-ADIBO-NOTA cold standard

Nonradioactive: ADIBO-NOTA ( $50 \mu \mathrm{L}$ of $1 \mathrm{mg} / \mathrm{mL}$ solution) was mixed with excess $\mathrm{CuCl}_{2}$ and $100 \mu \mathrm{L}$ of $0.1 \mathrm{M}$ EDTA solution was added to quench reaction.

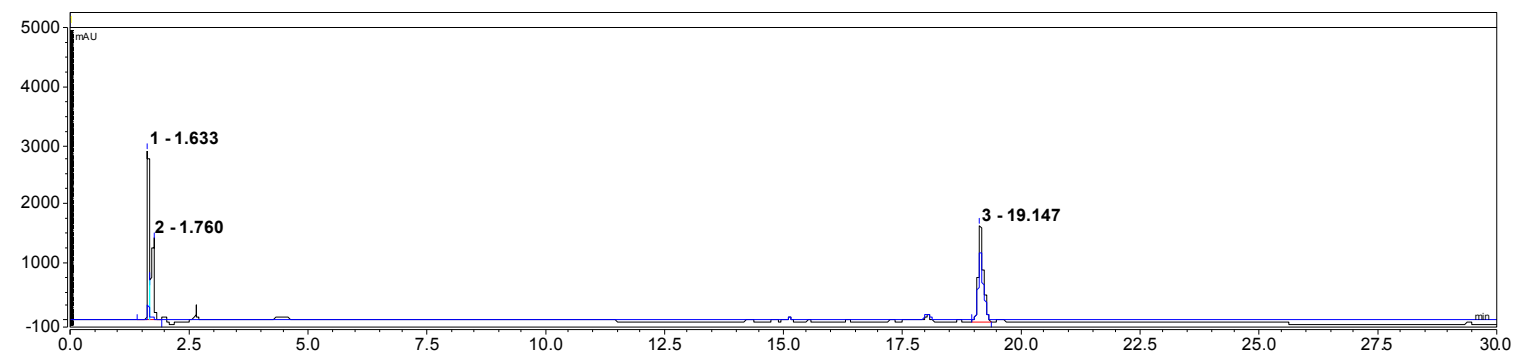

HPLC-Chromatogram: UV absorbance: $220 \mathrm{~nm}$ (black) and $254 \mathrm{~nm}$ (blue). Retention time: $19.15 \mathrm{~min}$

Figure S2d. ESI-MS of Cu-ADIBO-NOTA cold standard

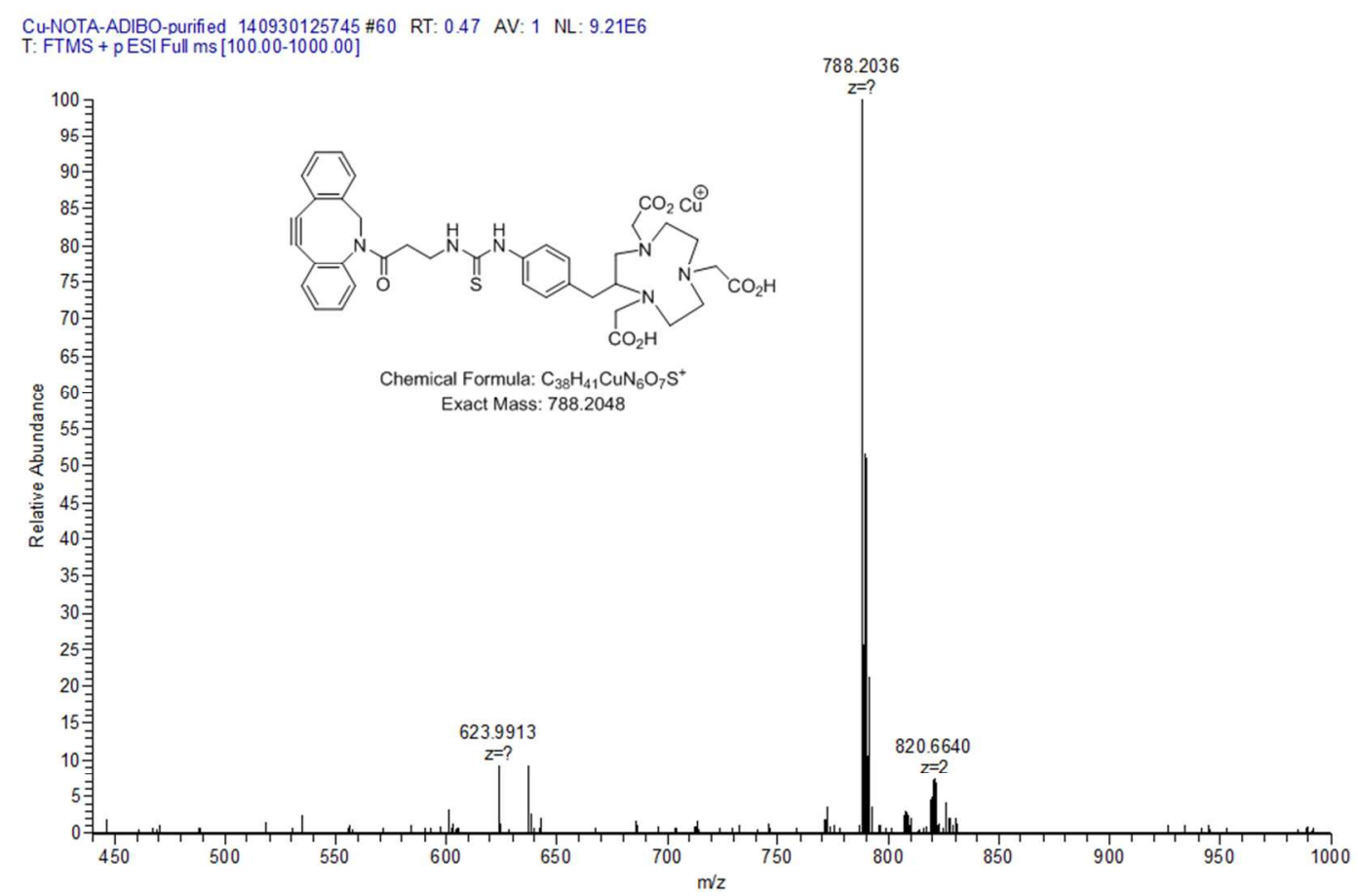

High Resolution Mass Spectrometry: (HRMS)(ESI-MS) $m / z$ : $[\mathrm{M}+\mathrm{Cu}]^{+}$calc'd for $\mathrm{C}_{38} \mathrm{H}_{41} \mathrm{CuN}_{6} \mathrm{O}_{7} \mathrm{~S}, 788.2048$; found 788.2036. 


\section{S3. Characterization of ${ }^{64} \mathrm{Cu}$-radiolabeled ADIBO-NOTA (7)}

Figure S3. Structure of $\left[{ }^{64} \mathrm{Cu}\right]-A D I B O-N O T A(7)$

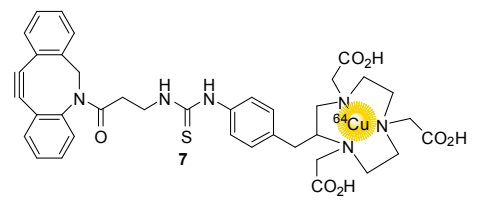

Figure S3a. HPLC-Chromatogram of $\left[{ }^{64} \mathrm{Cu}\right]-A D I B O-N O T A(7)$

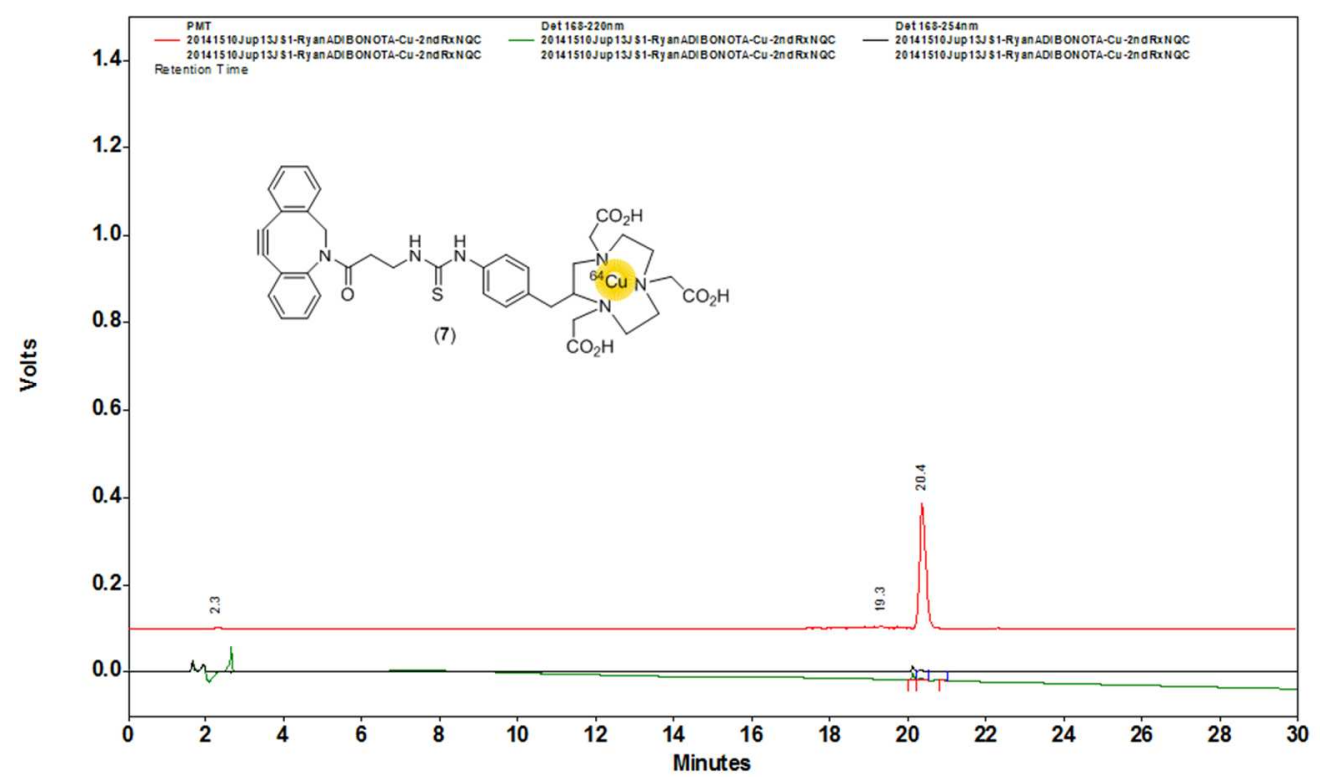

HPLC-Chromatogram: UV absorbance: $220 \mathrm{~nm}$ (green) and $254 \mathrm{~nm}$ (black). Radioactivity detector: PMT (RA) (red). Retention time: $20.4 \mathrm{~min}$ (RA). $3 \%$-free ${ }^{64} \mathrm{Cu}$ was observed at $2.3 \mathrm{~min}$ (RA) at the solvent front. 
Figure S3b. HPLC-Chromatogram of 7 spiked with cold standard

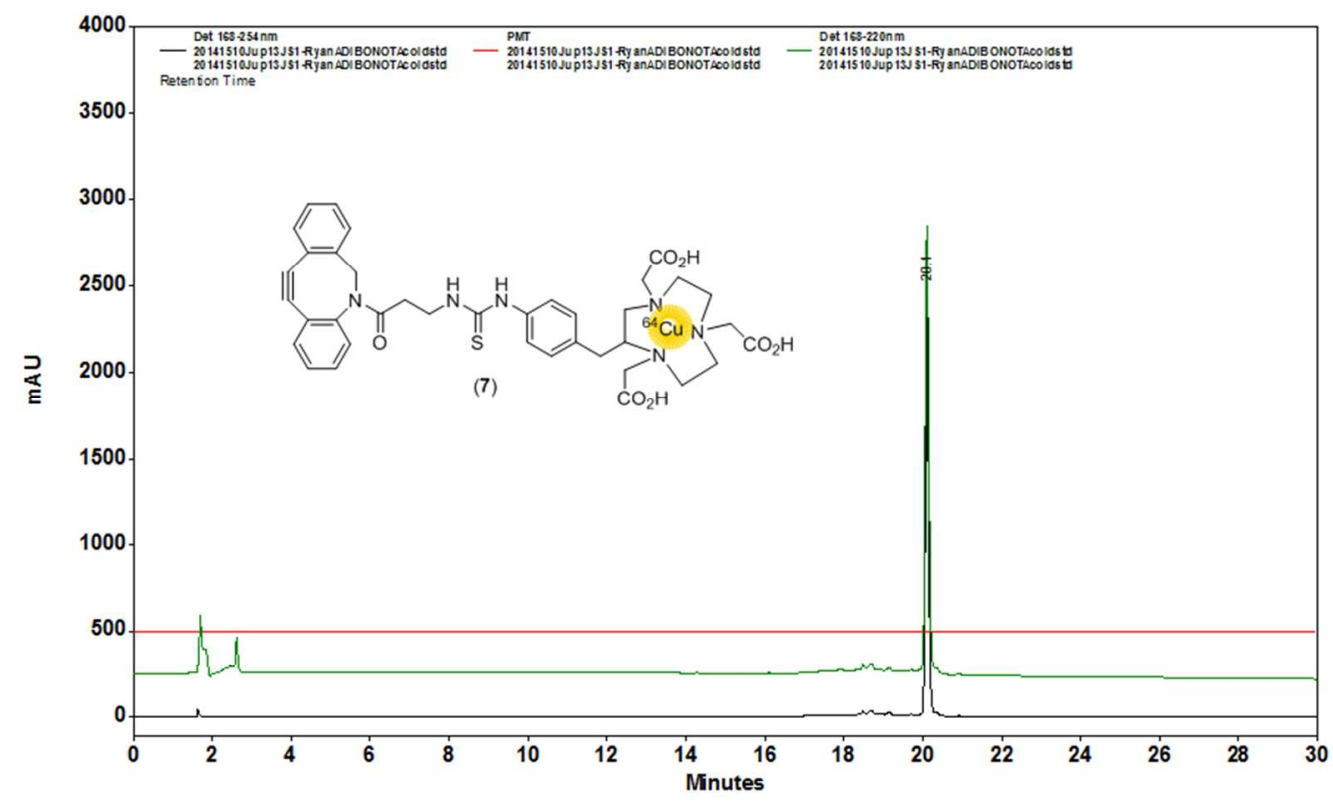

HPLC-Chromatogram: UV absorbance: $220 \mathrm{~nm}$ (green) and $254 \mathrm{~nm}$ (black). Radioactivity detector: PMT (RA) (red). Retention time: $20.1 \mathrm{~min}$ (RA)

Figure S3c. HPLC-Chromatogram of EDTA challenged spiked 7

The spiked sample of 7 was challenged with 0.1 M EDTA $(100 \mu \mathrm{L})$.

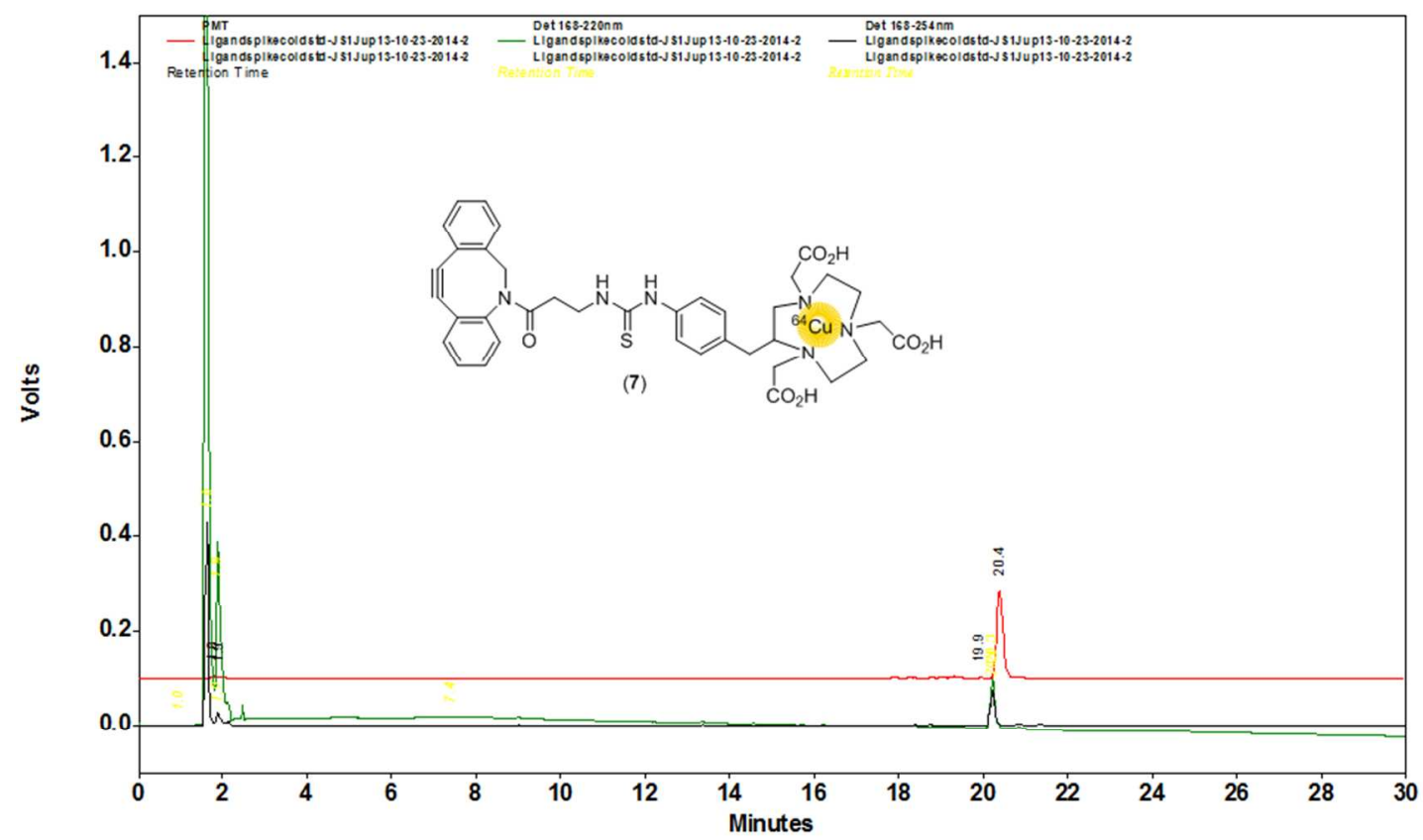

HPLC-Chromatogram: UV absorbance: $220 \mathrm{~nm}$ (green) and $254 \mathrm{~nm}$ (black). Radioactivity detector: PMT (RA) (red). Retention time: $19.9 \mathrm{~min}$ (UV), $20.4 \mathrm{~min}$ (RA). 
Figure S3d. iTLC of $\left[{ }^{64} \mathrm{Cu}\right]-A D I B O-N O T A(7)$

The crude product was challenged with $0.1 \mathrm{M} \mathrm{EDTA}(50 \mu \mathrm{L})$ and then spotted on a TLC and ran in a running solvent of $\mathrm{NH}_{4} \mathrm{OAc}$ buffer $\mathrm{pH}=8.0$.

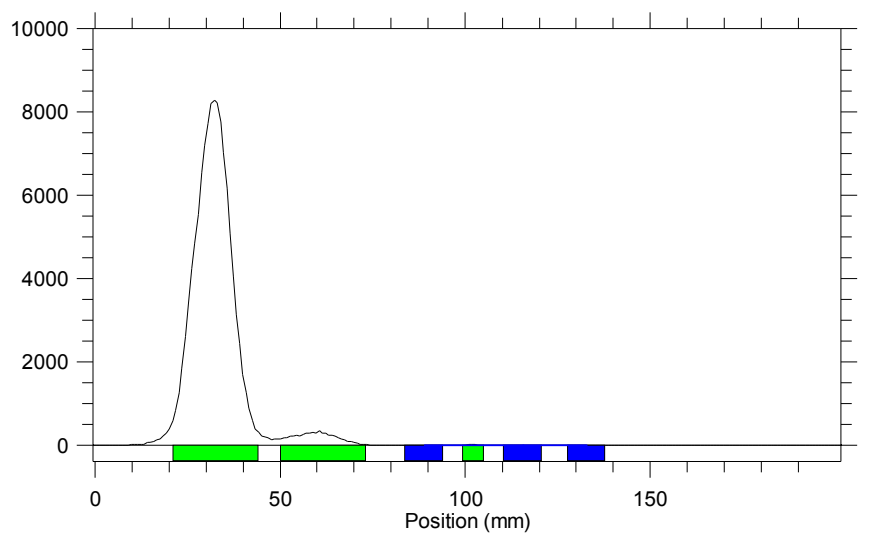

96\%-7 was observed at 20-40 mm , 4\%-free ${ }^{64} \mathrm{Cu}$-broad peak $50-70 \mathrm{~mm}$

\section{S4. Stability testing of $\left[{ }^{64} \mathrm{Cu}\right]-\mathrm{NPS}$}

Figure S4. Structure of $\left[{ }^{64} \mathrm{Cu}\right]-\mathrm{NPs}$

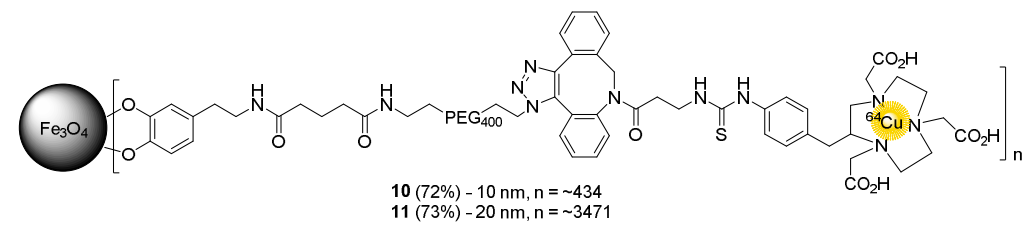

After clicking the radioactive ligand 7 to the NPs, the NPs were spin column purified with P6-size exclusion gel (Bio-Rad). The NPs were then filtered with a membrane filter molecular weight cut off of 40,000 . The filtrate was analyzed by HPLC and gamma counter. Similar traces were observed at all pH's thus a representative set is provided. 
Figure S4a. Representative HPLC-Chromatogram of $\left[{ }^{64} \mathrm{Cu}\right]-\mathrm{NPs}$ at $\mathrm{pH}-5.0$

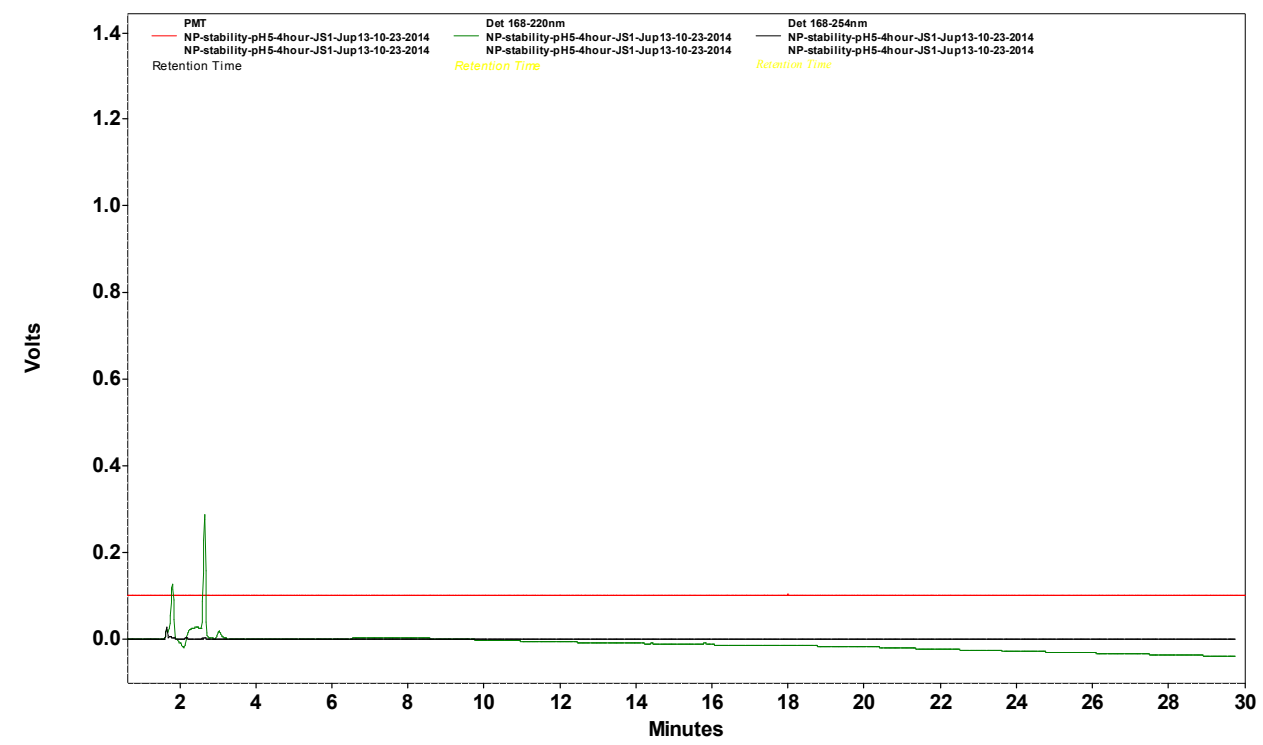

HPLC-Chromatogram: UV absorbance: $220 \mathrm{~nm}$ (green) and $254 \mathrm{~nm}$ (black). Radioactivity detector: PMT (RA) (red).

Figure S4b. Representative HPLC-Chromatogram $24 \mathrm{~h}$ after exposure to lettuce seedling The $24 \mathrm{~h}$ stability time point for the filtrate of the $\left[{ }^{64} \mathrm{Cu}\right]-\mathrm{NP}$-suspension exposed to the lettuce seedling.

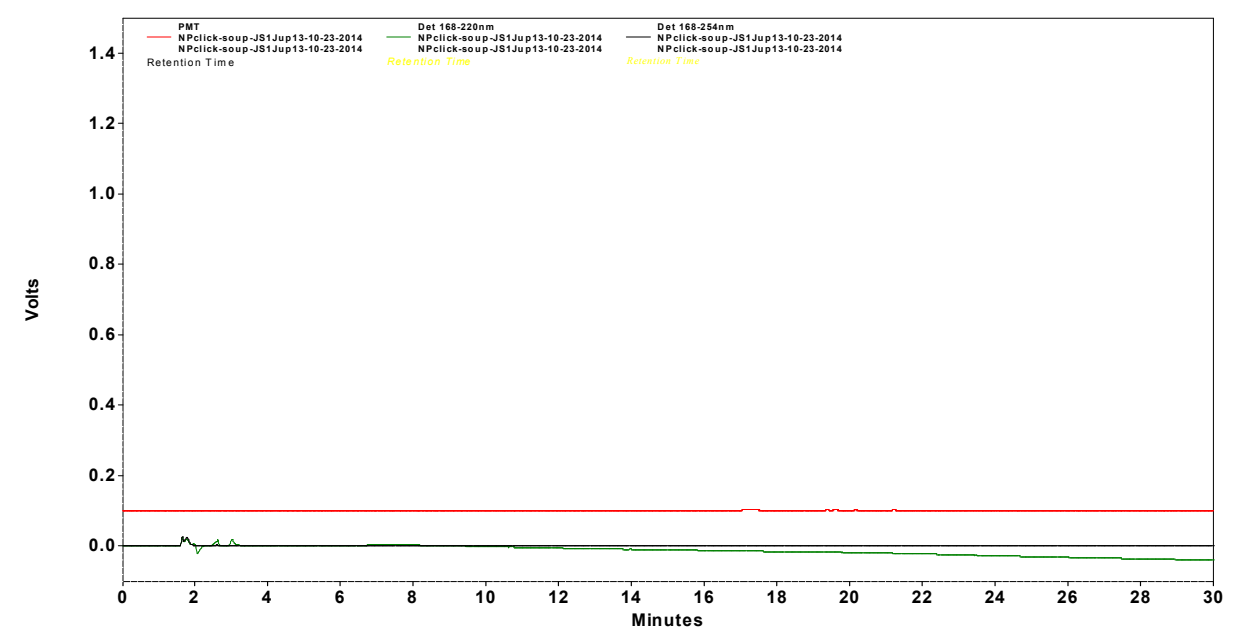

HPLC-Chromatogram: UV absorbance: $220 \mathrm{~nm}$ (green) and $254 \mathrm{~nm}$ (black). Radioactivity detector: PMT (RA) (red). 


\section{S5. Nanoparticle size/colloidal stability characterization}

Size determination of non-clicked and clicked NPs were all identical.

Table S5. Table of NP-size summary (DSL and TEM) and zeta-potential data

\begin{tabular}{|c|l|c|c|c|}
\hline Entry & \multicolumn{1}{|c|}{ Nanoparticle } & TEM-Radius & $\begin{array}{c}\text { DLS-Hydrodynamic } \\
\text { Radius }\end{array}$ & $\begin{array}{c}\text { zeta- } \\
\text { potential }\end{array}$ \\
\hline 1 & Non-clicked (8) & $9 \pm 2 \mathrm{~nm}$ & $76 \pm 27 \mathrm{~nm}$ & $-49.1 \mathrm{mV}$ \\
\hline 2 & Non-clicked (9) & $19 \pm 3 \mathrm{~nm}$ & $192 \pm 73 \mathrm{~nm}$ & $-43.1 \mathrm{mV}$ \\
\hline 3 & Clicked-NOTA (10) & $9 \pm 2 \mathrm{~nm}$ & $97 \pm 39 \mathrm{~nm}$ & $-40.4 \mathrm{mV}$ \\
\hline 4 & Clicked-NOTA (11) & $19 \pm 3 \mathrm{~nm}$ & $105 \pm 41 \mathrm{~nm}$ & $-42.9 \mathrm{mV}$ \\
\hline 5 & Clicked-Rhodamine (13) & $9 \pm 2 \mathrm{~nm}$ & $59 \pm 21 \mathrm{~nm}$ & $-48.6 \mathrm{mV}$ \\
\hline 6 & Clicked-Rhodamine (14) & $19 \pm 3 \mathrm{~nm}$ & $65 \pm 23 \mathrm{~nm}$ & $-55.2 \mathrm{mV}$ \\
\hline
\end{tabular}

Figure S5. TEM images and size distribution graph of NPs 8 and $\mathbf{9}$

A.

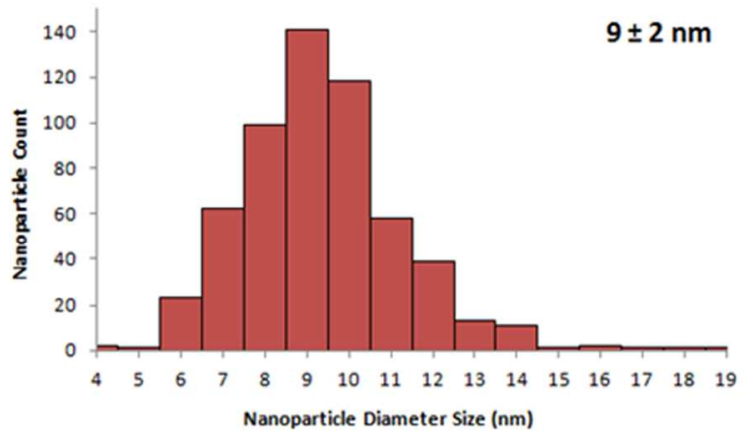

B.

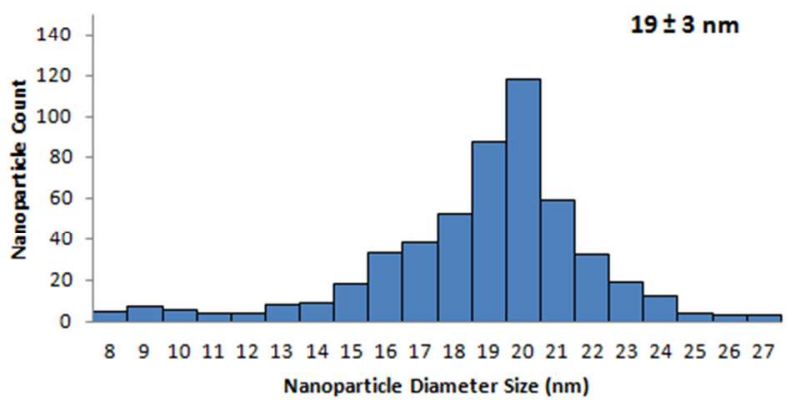

A. Size distribution graph of starting NPs $(8,10 \mathrm{~nm})$

B. Size distribution graph of starting NPs $(9,20 \mathrm{~nm})$ 
Figure S5a. TEM images of $\left[{ }^{64} \mathrm{Cu}\right]-\mathrm{NPs} \mathbf{1 0}$ and $\mathbf{1 1}$.

TEM-images are representative as all sets of each size appear identical.

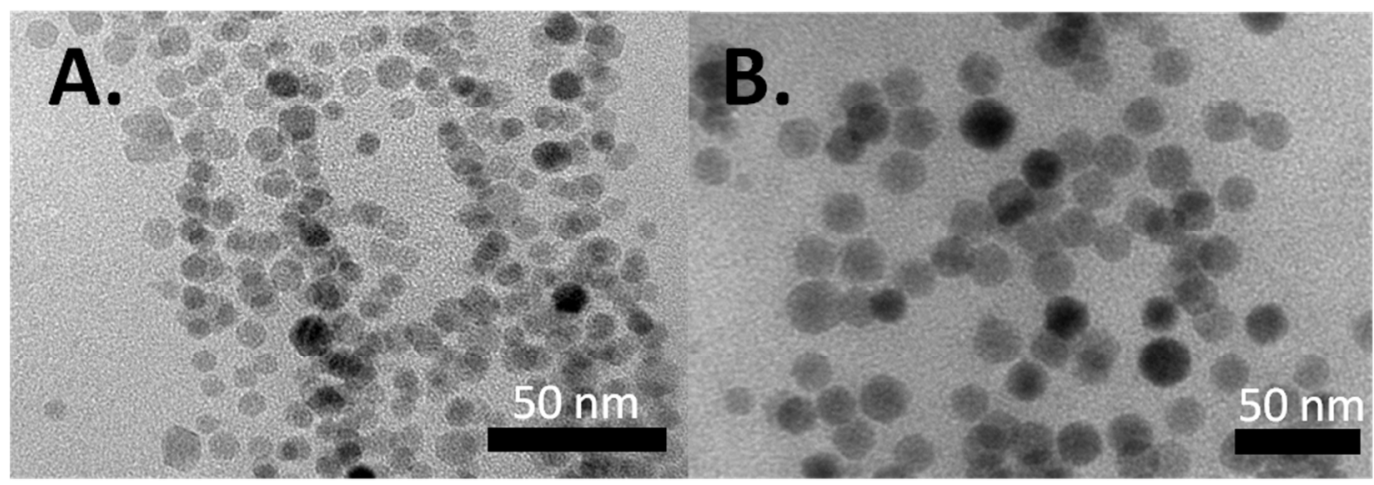

A. Size $10 \mathrm{~nm}-\left[{ }^{64} \mathrm{Cu}\right]-N P s(\mathbf{1 0})$ B. Size $20 \mathrm{~nm}-\left[{ }^{64} \mathrm{Cu}\right]-N P s(\mathbf{1 1})$

\section{S6. Summary of biodistribution data in lettuce seedling}

Table S6. Summary of biodistribution data in lettuce seedling

All data are expressed as using decay corrected activity.

\begin{tabular}{|c|c|c|c|c|c|c|c|}
\hline \multicolumn{2}{|c|}{ NP Size } & \multicolumn{3}{|c|}{$\left[{ }^{64} \mathrm{Cu}\right]-\mathrm{NPs}(10)(10 \mathrm{~nm})$} & \multicolumn{3}{|c|}{$\left[{ }^{64} \mathrm{Cu}\right]-\mathrm{NPs}(11)(20 \mathrm{~nm})$} \\
\hline Time & Lettuce & $\mathrm{nCi} / \mathrm{g}$ & \#NPs/g & $\mu \mathrm{g} N P s / g$ & $\mathrm{nCi} / \mathrm{g}$ & \#NPs/g & $\mu g$ NPs/g \\
\hline \multirow{3}{*}{$0.25 \mathrm{~h}$} & Intact & $2043 \pm 262$ & $5.74 \mathrm{e} 11 \pm 7.36 \mathrm{e} 10$ & $1.50 \pm 0.19$ & $2065 \pm 121$ & $8.78 \mathrm{e} 10 \pm 5.14 \mathrm{e} 9$ & $1.83 \pm 0.11$ \\
\hline & Root & $1967 \pm 255$ & $5.53 \mathrm{e} 11 \pm 7.16 \mathrm{e} 10$ & $1.45 \pm 0.19$ & $1995 \pm 111$ & $8.48 \mathrm{e} 10 \pm 4.72 \mathrm{e} 9$ & $1.77 \pm 0.10$ \\
\hline & Cotyledons & $77 \pm 7$ & $2.16 \mathrm{e} 10 \pm 1.97 \mathrm{e} 9$ & $0.06 \pm 0.01$ & $67 \pm 8$ & $2.85 \mathrm{e} 9 \pm 3.40 \mathrm{e} 8$ & $0.06 \pm 0.01$ \\
\hline \multirow{3}{*}{$0.5 \mathrm{~h}$} & Intact & $2369 \pm 454$ & $6.65 \mathrm{e} 11 \pm 1.28 \mathrm{e} 11$ & $1.74 \pm 0.33$ & $2782 \pm 354$ & $1.18 \mathrm{e} 11 \pm 1.50 \mathrm{e} 10$ & $2.47 \pm 0.31$ \\
\hline & Root & $2259 \pm 432$ & $6.35 \mathrm{e} 11 \pm 1.21 \mathrm{e} 11$ & $1.66 \pm 0.32$ & $2713 \pm 345$ & $1.15 \mathrm{e} 11 \pm 1.47 \mathrm{e} 10$ & $2.41 \pm 0.31$ \\
\hline & Cotyledons & $110 \pm 22$ & $3.09 \mathrm{e} 10 \pm 6.18 \mathrm{e} 9$ & $0.08 \pm 0.02$ & $68 \pm 8$ & $2.89 \mathrm{e} 9 \pm 3.40 \mathrm{e} 8$ & $0.06 \pm 0.01$ \\
\hline \multirow{3}{*}{$1 \mathrm{~h}$} & Intact & $5567 \pm 2124$ & $1.56 \mathrm{e} 12 \pm 5.97 \mathrm{e} 11$ & $4.10 \pm 1.56$ & $4160 \pm 128$ & $1.77 \mathrm{e} 11 \pm 5.44 \mathrm{e} 9$ & $3.70 \pm 0.11$ \\
\hline & Root & $5396 \pm 2085$ & $1.52 \mathrm{e} 12 \pm 5.86 \mathrm{e} 11$ & $3.97 \pm 1.53$ & $3768 \pm 76$ & $1.60 \mathrm{e} 11 \pm 3.23 \mathrm{e} 9$ & $3.35 \pm 0.07$ \\
\hline & Cotyledons & $171 \pm 46$ & $4.80 \mathrm{e} 10 \pm 1.29 \mathrm{e} 10$ & $0.13 \pm 0.03$ & $392 \pm 52$ & $1.67 \mathrm{e} 10 \pm 2.21 \mathrm{e} 9$ & $0.35 \pm 0.05$ \\
\hline \multirow{3}{*}{$2 \mathrm{~h}$} & Intact & $5310 \pm 1406$ & $1.49 \mathrm{e} 12 \pm 3.95 \mathrm{e} 11$ & $3.91 \pm 1.03$ & $4488 \pm 816$ & $1.91 \mathrm{e} 11 \pm 3.47 \mathrm{e} 10$ & $3.99 \pm 0.72$ \\
\hline & Root & $4307 \pm 1379$ & $1.21 \mathrm{e} 12 \pm 3.87 \mathrm{e} 11$ & $3.17 \pm 1.01$ & $4111 \pm 725$ & $1.75 \mathrm{e} 11 \pm 3.08 \mathrm{e} 10$ & $3.65 \pm 0.64$ \\
\hline & Cotyledons & $103 \pm 28$ & $2.89 \mathrm{e} 10 \pm 7.87 \mathrm{e} 9$ & $0.08 \pm 0.02$ & $377 \pm 91$ & $1.60 \mathrm{e} 10 \pm 3.87 \mathrm{e} 9$ & $0.33 \pm 0.08$ \\
\hline \multirow{3}{*}{$4 \mathrm{~h}$} & Intact & $4034 \pm 2015$ & $1.13 \mathrm{e} 12 \pm 5.66 \mathrm{e} 11$ & $2.97 \pm 1.48$ & $3861 \pm 139$ & $1.64 \mathrm{e} 11 \pm 5.91 \mathrm{e} 9$ & $3.43 \pm 0.12$ \\
\hline & Root & $3817 \pm 1955$ & $1.07 \mathrm{e} 12 \pm 5.49 \mathrm{e} 11$ & $2.81 \pm 1.44$ & $3734 \pm 98$ & $1.59 \mathrm{e} 11 \pm 4.17 \mathrm{e} 9$ & $3.32 \pm 0.09$ \\
\hline & Cotyledons & $218 \pm 61$ & $6.12 \mathrm{e} 10 \pm 1.71 \mathrm{e} 10$ & $0.16 \pm 0.04$ & $528 \pm 42$ & $2.24 \mathrm{e} 10 \pm 1.79 \mathrm{e} 9$ & $0.47 \pm 0.04$ \\
\hline \multirow{3}{*}{$12 \mathrm{~h}$} & Intact & $6329 \pm 2069$ & $1.78 \mathrm{e} 12 \pm 5.81 \mathrm{e} 11$ & $4.66 \pm 1.52$ & $5735 \pm 2072$ & $2.44 \mathrm{e} 11 \pm 8.81 \mathrm{e} 10$ & $5.09 \pm 1.84$ \\
\hline & Root & $5070 \pm 1817$ & $1.42 \mathrm{e} 12 \pm 5.10 \mathrm{e} 11$ & $3.73 \pm 1.34$ & $5164 \pm 2035$ & $2.19 \mathrm{e} 11 \pm 8.65 \mathrm{e} 10$ & $4.59 \pm 1.81$ \\
\hline & Cotyledons & $1259 \pm 251$ & $3.54 \mathrm{e} 11 \pm 7.05 \mathrm{e} 10$ & $0.93 \pm 0.18$ & $571 \pm 37$ & $2.43 \mathrm{e} 10 \pm 1.57 \mathrm{e} 9$ & $0.51 \pm 0.03$ \\
\hline \multirow{3}{*}{$24 \mathrm{~h}$} & Intact & $10276 \pm 1152$ & $2.89 \mathrm{e} 12 \pm 3.24 \mathrm{e} 11$ & $7.56 \pm 0.85$ & $6369 \pm 1220$ & $2.71 \mathrm{e} 11 \pm 5.19 \mathrm{e} 10$ & $5.66 \pm 1.08$ \\
\hline & Root & $8350 \pm 857$ & $2.35 \mathrm{e} 12 \pm 2.41 \mathrm{e} 11$ & $6.15 \pm 0.63$ & $5553 \pm 1159$ & $2.36 \mathrm{e} 11 \pm 4.93 \mathrm{e} 10$ & $4.93 \pm 1.03$ \\
\hline & Cotyledons & $1927 \pm 275$ & $5.41 \mathrm{e} 11 \pm 7.73 \mathrm{e} 10$ & $1.42 \pm 0.20$ & $817 \pm 60$ & $3.47 \mathrm{e} 10 \pm 2.55 \mathrm{e} 9$ & $0.73 \pm 0.05$ \\
\hline
\end{tabular}


Figure S6. Biodistribution in intact lettuce seedling over time

Biodistribution graph of activity/gram of lettuce seedlings over time for the intact plant with data expressed as decay-corrected activity per gram of lettuce after washing.

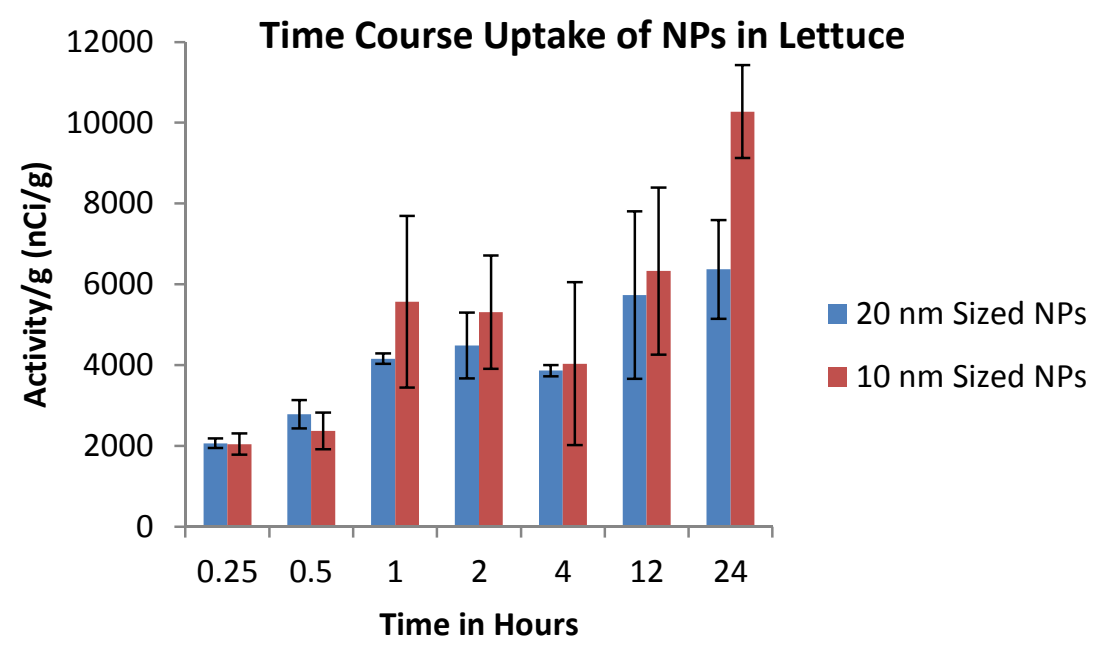

\section{S7. Autoradiography imaging of duckweed}

Duckweed (L. (Spirodela) punctate) was grown hydroponically using the Hoagland nutrient media in a growth chamber at $25{ }^{\circ} \mathrm{C}$ with a 16-h-light photoperiod. Autoradiography images of duckweed exposed to $\left[{ }^{64} \mathrm{Cu}\right]-\mathrm{NPs}(\mathbf{1 1}, \mathbf{2 0} \mathrm{nm})$ for a $2 \mathrm{~h}$ uptake period.

Figure S7. Autoradiography images of duckweed

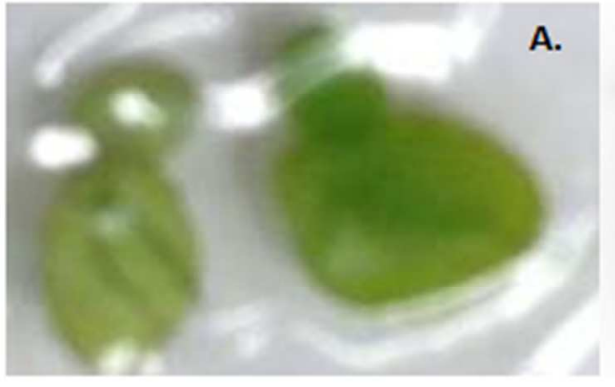

B.

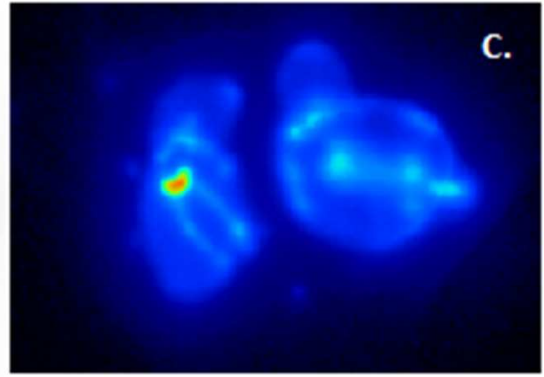

A. Photographic image of duckweed. B. Black and white color scale autoradiography image of duckweed. C. Rainbow color scale autoradiography image of duckweed. white-highest activity to dark blue- lowest activity. 


\section{S8. Optical image of uptake of dye-labeled NPs in lettuce seedling}

The fluorescently labeled NPs $\mathbf{1 3}$ and $\mathbf{1 4}$ were used to further substantiate the transport of intact-NPs into lettuce. NPs 13 and 14 were diluted to $\sim 48 \mathrm{mg} \mathrm{L}^{-1}$ per plant with a total volume of $350 \mu \mathrm{L}$. The bottom $2 \mathrm{~cm}$ of the lettuce root was submerged into the optical NPs suspension and covered with black construction paper for imaging. The autolumenescent wavelengths were filtered out and the optical image collected on an IVIS-photospectrometer.

Figure S8. Uptake of sulforhodamine-labeled NPs (14) in lettuce seedling

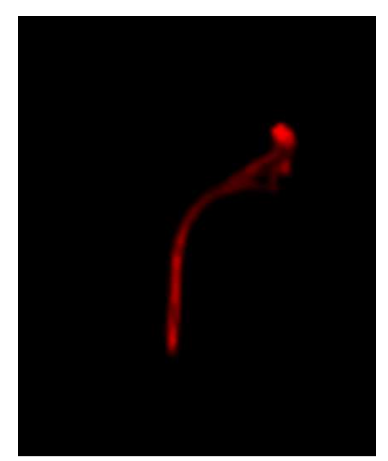




\section{S9. Additional autoradiography images}

Figure S9. Additional autoradiography images showing bends in root containing areas of higher radioactivity

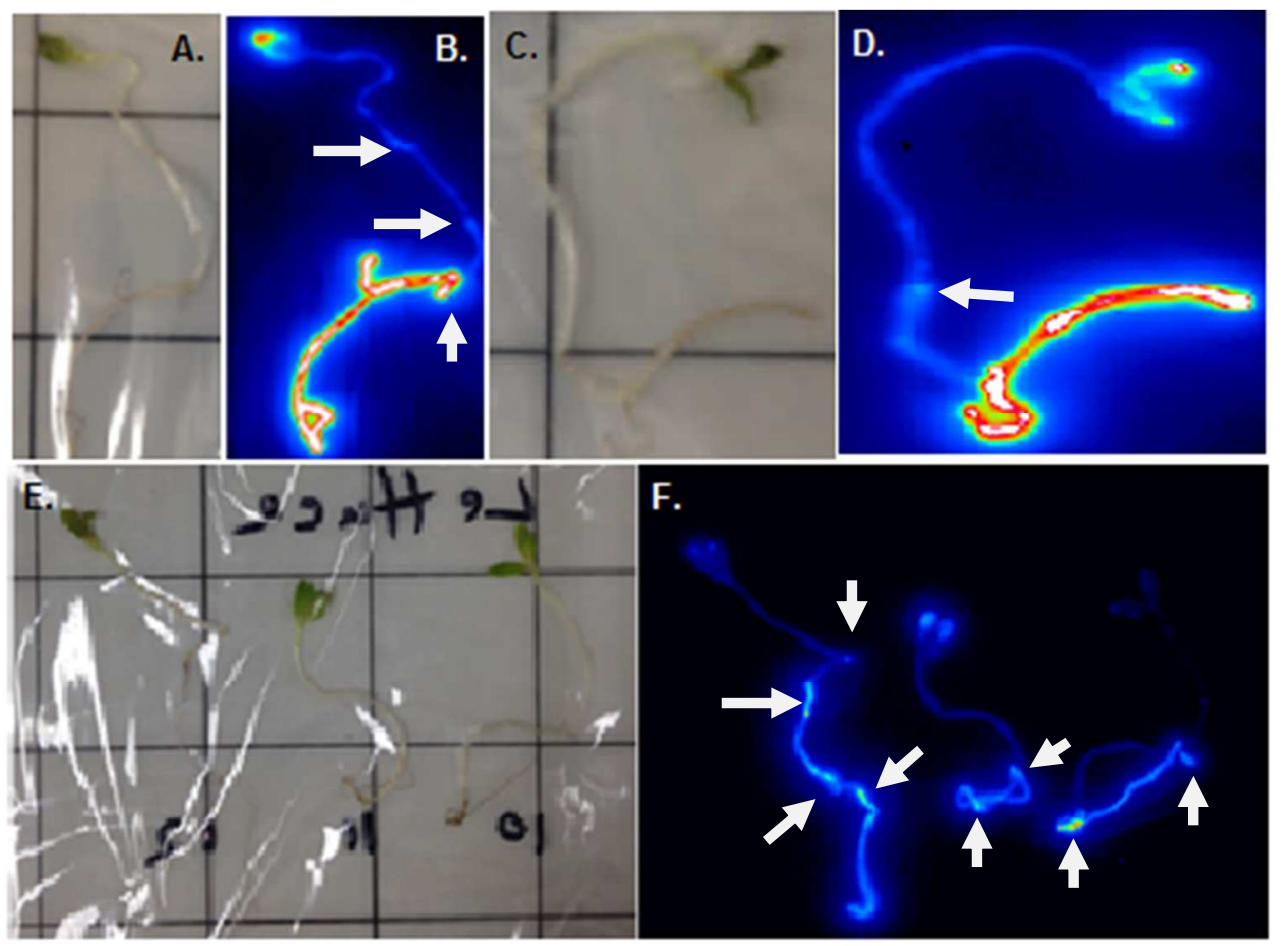

A,C,E. Photographic image of lettuce seedlings. B,D. Corresponding autoradiography image of lettuce seedlings exposed to $\left[{ }^{64} \mathrm{Cu}\right]-\mathrm{NPs}(\mathbf{1 1}, 20 \mathrm{~nm})$ for $2 \mathrm{~h}$. F. Corresponding autoradiography image of lettuce seedlings exposed to $\left[{ }^{64} \mathrm{Cu}\right.$-NPs $(\mathbf{1 1}, 20 \mathrm{~nm})$ for $0.25 \mathrm{~h}$. Color scale rainbow: white-highest radioactivity to dark blue-lowest radioactivity, white arrows indicate areas of increased radioactivity around regions where the root contained a bend or turn. 


\section{S10. Autoradiography image of plants given $\left[{ }^{64} \mathrm{Cu}\right] \mathrm{CuCl}_{2}$}

Plants contained much higher activity that was more uniformly spread when exposed to radioactive $\left[{ }^{64} \mathrm{Cu}\right] \mathrm{CuCl}_{2}$ solution containing $\sim 30 \mu \mathrm{Ci}$ of radioactivity for a $2 \mathrm{~h}$ uptake time period.

Figure S10. Autoradiography image of lettuce seedling given $\left[{ }^{64} \mathrm{Cu}\right] \mathrm{CuCl}_{2}$

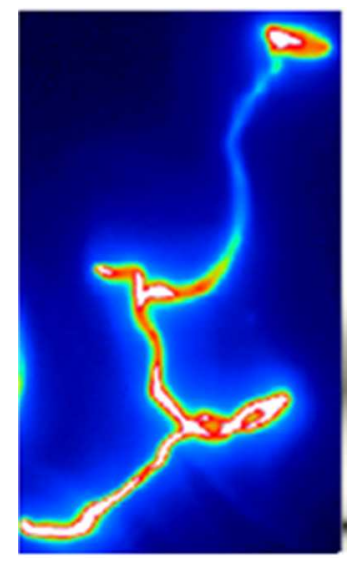

Color scale rainbow: white-highest radioactivity to dark blue-lowest radioactivity

Table S10. Biodistribution data for lettuce seedling given $\left[{ }^{64} \mathrm{Cu}\right] \mathrm{CuCl}_{2}$

\begin{tabular}{|c|c|}
\hline Lettuce & $\mathrm{nCi} / \mathrm{g}$ \\
\hline Intact & $110647 \pm 7263$ \\
\hline Root & $102566 \pm 5534$ \\
\hline Cotyledons & $8081 \pm 1725$ \\
\hline
\end{tabular}

Figure S10a. Autoradiography image of duckweed given $\left[{ }^{64} \mathrm{Cu}\right] \mathrm{CuCl}_{2}$
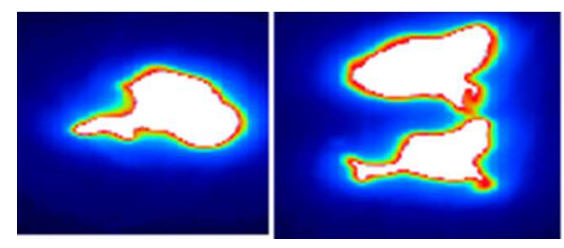

Autoradiography image of three duckweeds. Color scale rainbow: white-highest radioactivity to dark blue-lowest radioactivity 